\title{
Recent progress in the development of upconversion nanomaterials in bioimaging and disease treatment
}

\author{
Gaofeng Liang ${ }^{*}$, Haojie Wang ${ }^{1}$, Hao Shi ${ }^{2}$, Haitao Wang ${ }^{3}$, Mengxi Zhu' ${ }^{1}$, Aihua Jing ${ }^{2}$, Jinghua Li \\ and Guangda Li
}

\begin{abstract}
Multifunctional lanthanide-based upconversion nanoparticles (UCNPs), which feature efficiently convert low-energy photons into high-energy photons, have attracted considerable attention in the domain of materials science and biomedical applications. Due to their unique photophysical properties, including light-emitting stability, excellent upconversion luminescence efficiency, low autofluorescence, and high detection sensitivity, and high penetration depth in samples, UCNPs have been widely applied in biomedical applications, such as biosensing, imaging and theranostics. In this review, we briefly introduced the major components of UCNPs and the luminescence mechanism. Then, we compared several common design synthesis strategies and presented their advantages and disadvantages. Several examples of the functionalization of UCNPs were given. Next, we detailed their biological applications in bioimaging and disease treatment, particularly drug delivery and photodynamic therapy, including antibacterial photodynamic therapy. Finally, the future practical applications in materials science and biomedical fields, as well as the remaining challenges to UCNPs application, were described. This review provides useful practical information and insights for the research on and application of UCNPs in the field of cancer.
\end{abstract}

Keywords: Upconversion, PDT, Biomedical applications, Drug delivery, Bioimaging, aPDT

\section{Introduction}

Traditional surgery and chemotherapy often lead to infection and recurrently [1]. Biotherapeutics including the emerging photodynamic therapy (PDT), which involves precise treatment of tumor cells by in situ generations of singlet oxygen, have proven to be effective disease treatment techniques. These efficient and promising therapies form a new category in the field of disease therapy [2-4]. Before disease treatment was administered, a variety of imaging technologies were employed for cancer diagnosis, including computed tomography (CT) scan, X-ray, ultrasound, magnetic resonance imaging (MRI), positron

*Correspondence: Igfeng990448@163.com

${ }^{1}$ Medical College, Henan University of Science and Technology, Luoyang 471023, Henan, China

Full list of author information is available at the end of the article emission tomography (PET) scan, and fluorescence imaging. The commonly used imaging probes, such as fluorescent dyes and fluorescent proteins, have gained a great deal of appreciation. Nevertheless, they are plagued with deficient detection sensitivity, fast photobleaching, and high toxicity, and have no treatment effect whatsoever. It was difficult to find a dual functional material that can serve as an imaging probe and a drug carrier simultaneously. As an effective drug delivery carrier, it should satisfy the following criteria: (1) effective drug delivery, (2) good biocompatibility, and (3) good stability of in vivo circulation [5-7]. Recently, the rapid development of nanomedicine has opened up a new way to overcome these shortcomings. Nanobiomaterials have become a hot topic in the biomedical-application fields due to their great potential for formulating anticancer drugs. Engineered nanomaterials, exhibiting enhanced permeability 
and retention (EPR) effect, biocompatibility, and low toxicity, could be used in biomedical applications, including biomedical diagnosing and disease treatment $[8,9]$.

These nanomaterials typically possess unique optical, magnetic, and acoustic properties, which render them a universal tool in biomedical fields such as bioanalytical science, biomedical imaging and imaging-guided therapy [10-12]. Light-responsive nanomaterials such as quantum dots, metal nanoparticles, have become the optimal candidates because of their advantages including better optical properties i.e. brighter luminescence, small size, good biocompatibility, easy modifications, high sensitivity and higher photostability. These merits enabled the sensitive detection of biological samples and the labeling of reporter molecules [13, 14]. Typically, however, the use of these light-responsive nanomaterials has several limitations, such as background fluorescence interference, easy photolysis, weak penetration, shortly fluorescence time, and long-term toxicity $[15,16]$. Upconversion luminescent nanoparticles (UCNPs) exhibit anti-Stokes luminescent, which can convert the near-infrared (NIR) light into visible light. UCNPs have high chemical stability and can be used as fluorescence probes in a variety of complex organisms, facilitating the bioassay process. Moreover, UCNPs could be easily functionalized by linking specific targeting ligands (e.g., peptides, antibodies and small-molecule drugs) to the surface and could be used as probes to detect and target specific cells with high sensitivity and selectivity $[17,18]$.

Luminescent nanoparticles are effectively used as optical imaging guidance for tumor therapy [19]. UCNPs are an upgraded alternative to traditional optical imaging materials due to several other advantages, such as weak photobleaching, low self-illuminating background fluorescence, deep tissue penetration, and minimal photodamage [20-24]. Moreover, as a new generation of imaging agents, UCNPs are widely used in PDT, upconversion luminescence (UCL), MRI, X-ray CT imaging, photoacoustic (PA) imaging, NIR thermal imaging, upconversion luminescence imaging, photothermal therapy (PTT), chemotherapy and radiotherapy. Increasing studies have focused on their application in PDT, because they can act as a photosensitizer in photodynamic therapy [25-30]. In addition, they can be applied as drug carriers for bioimaging therapeutic drugs or genes (such as doxorubicin, siRNA, DNA, and microRNA) or photosensitizers. Our group has developed a UCNP-based miRNA delivery vector and achieved excellent gene therapy effect on in vivo and in vitro colorectal cancer models [31]. More importantly, UCNP as the protagonist of antibacterial photodynamic therapy (aPDT) has played a pivotal role in the treatment of bacterial infectious diseases, such as periodontitis and Staphylococcus aureus infections, that are intractable and difficult to eradicate [32]. The development of nanomaterials that exhibit both good UCL efficiency and good functionality is undoubtedly a challenge for material scientists, physicists and chemists. Moreover, methods for applying such nanomaterials with unique UCL characteristics to biological, medical, and imaging detection will also attract the interest of biologists and medical scientists in the field of detection.

Although UCNP nanosystems designed for cancer imaging or drug delivery have been summarized in several review articles, a review focused on multifunctional UCNPs designed for both imaging and drug delivery in therapeutics is still lacking. Herein, we systematically summarized the recent progress in the development of UCNPs and introduced the fundamental aspects of UCNP. We then focused on their applications in drug delivery and PDT therapy and the construction of targeted drug delivery and aPDT applications in conjunction with related research. Finally, we highlighted the remaining challenges and speculated on future practical applications of UCNPs in the fields of materials science and biomedical engineering.

\section{The fundamentals of UCNP composition}

The unique optical properties of UCNPs are highly dependent on their material composition. Figure 1a illustrates lanthanide-based UCNPs in terms of their matrix material, sensitized ions, and activated ions [33, 34]. The activated ions mainly provide luminescent centers; the sensitized ions absorb NIR light (the absorbed light energy can be transferred to the activated ions to facilitate the emission of light); and the matrix mainly provides a crystalline host lattice structure for activating ions and sensitizing ions to the correct place, giving it the appropriate light conditions. As Fig. 1b shows, attaching an organic dye to the surface of the doped upconverted nanoparticles by electronic interaction and physical absorption can be used to collect the excitation light so that the excitation wavelength can be effectively extended [35]. Moreover, numerous studies have shown that the doping ratio of different ions will also affect the excitation and emission wavelength of UCL (Table 1).

The materials commonly used to synthesize UCNPs mainly include oxides, fluorides and chlorides [36-39]. The choice of metal-fluorides-based host materials has demonstrated dependable chemical stability, and the dopant ions used in the materials were a necessary condition for a stable host lattice [40]. Among many host matrix materials reported, $\mathrm{NaXF}_{4}$ is the most common choice for the preparation of high-quality lattice upconversion materials due to its advantages of high chemical stability and low photon energy $[41,42]$. The most critical parameter in the consideration of UCL efficiency is the 
a

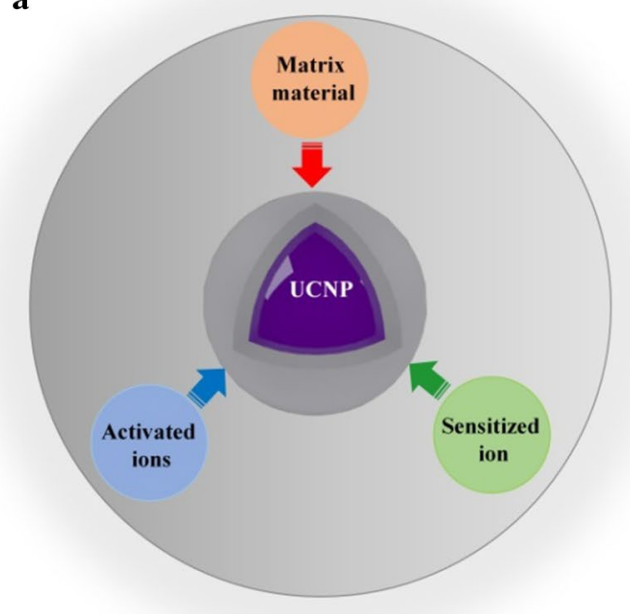

b

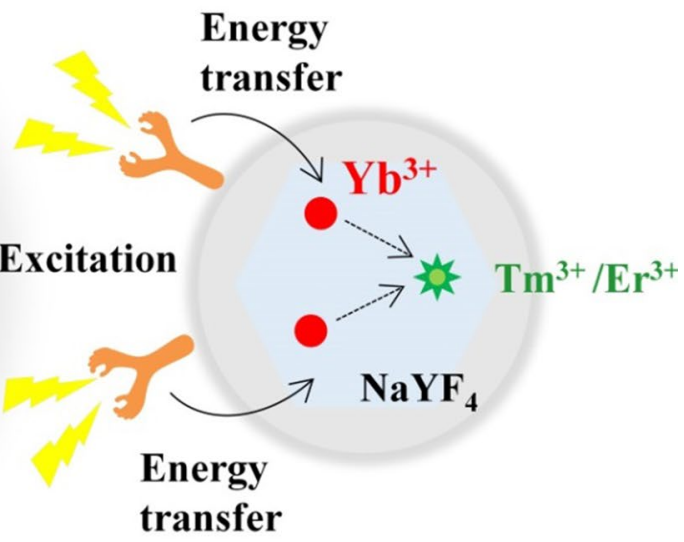

Fig. 1 a The basic composition of UCNPs and $\mathbf{b}$ schematic illustration of the mechanism of organic dye-sensitized UCNPS

Table 1 The doping ratio of different ions of UCNP and their major emission wavelength

\begin{tabular}{|c|c|c|c|c|c|c|c|}
\hline \multicolumn{4}{|c|}{ Dopant ions and compositional ion } & \multicolumn{3}{|c|}{ Major emissions (nm) } & \multirow[t]{2}{*}{ References } \\
\hline Host lattice & Sensitizer & Activator & Shell & Blue & Green & Red & \\
\hline \multirow[t]{3}{*}{$\beta-\mathrm{NaYF}_{4}$} & $20 \% \mathrm{Yb}$ & $2 \% \mathrm{Er}$ & & 450,476 & 520 & 654 & Ref. [51] \\
\hline & $20 \% \mathrm{Yb}$ & $0.2 \% \operatorname{Tm}$ & & & 540 & & Ref. [38] \\
\hline & $20 \% \mathrm{Yb}$ & $2 \% \mathrm{Ho}$ & & & 541 & & Ref. [38] \\
\hline \multirow[t]{2}{*}{$\beta-\mathrm{NaYF}_{4}$} & $25 \% \mathrm{Yb}$ & $0.3 \% \mathrm{Tm}$ & $20 \% \mathrm{Yb}, 2 \% \mathrm{Er}$ & 450 & 520 & 653 & Ref.[52] \\
\hline & & & & 475 & 540 & & \\
\hline $\mathrm{Li}^{+}$doped $\beta-\mathrm{NaYF}_{4}$ & $20 \% \mathrm{Yb}$ & $0.5 \% \mathrm{Tm}$ & & 452,479 & & 650 & Ref.[39] \\
\hline $\mathrm{Mn}^{+}$doped $\beta-\mathrm{NaYF}_{4}$ & $20 \% \mathrm{Yb}$ & $2 \% \mathrm{Er}$ & & & & 657 & Ref. [53] \\
\hline \multirow[t]{4}{*}{$\beta-\mathrm{NaYF}_{4}$} & $18.6 \% \mathrm{Yb}$ & $2.2 \% \operatorname{Er}$ & TRITC-SiO 2 & 407 & & & Ref. [40] \\
\hline & $25 \% Y b$ & $0.3 \% \mathrm{Tm}$ & $\mathrm{SiO}_{2}$ & 450,479 & 521,539 & 651 & Ref. [54] \\
\hline & $25 \% \mathrm{Yb}$ & $0.3 \% \mathrm{Tm}$ & FITC- $\mathrm{SiO}_{2}$ & 450,479 & $521,539,580$ & 651 & Ref. [41] \\
\hline & $25 \% \mathrm{Yb}$ & $0.3 \% \mathrm{Tm}$ & $\mathrm{QD}-\mathrm{SiO}_{2}$ & 450,479 & 540 & 605 & Ref. [41] \\
\hline \multirow[t]{3}{*}{$\mathrm{a}-\mathrm{NaYF}_{4}$} & $20 \% \mathrm{Yb}$ & $2 \% \mathrm{Er}$ & & 411 & & 660 & Ref. [55] \\
\hline & $20 \% \mathrm{Yb}$ & $0.2 \% \mathrm{Tm}$ & & 450 & 540 & 644 & Ref. [42] \\
\hline & $20 \% \mathrm{Yb}$ & $0.2 \% \mathrm{Er}$ & & 475 & 525 & 693 & Ref. [42] \\
\hline
\end{tabular}

cross-section of the sensitizer ions used to absorb NIR; generally, most lanthanide ions had very small absorption cross-sections in the NIR spectral region, which cannot produce sufficient UC efficiency [43]. However, $\mathrm{Yb}^{3+}$ or $\mathrm{Nd}^{3+}$, which have larger absorption cross-sections, can completely transfer the absorbed energy to adjacent excited ions in the crystal lattice, which may eliminate the problems associated with the weak absorption of activator ions $[44,45]$. The most common activating ions for the lanthanide ion $\mathrm{Yb}^{3+}$ in combination with the UC system are $\mathrm{Er}^{3+}, \mathrm{Tm}^{3+}$ or $\mathrm{Ho}^{3+}$ and so on. Activated ions are essential to the entire UC emission process [46]. The activator is responsible for emitting visible light and ultraviolet light from NIR light absorbed by sensitized ion conversion, making $\mathrm{Er}^{3+}$ or $\mathrm{Tm}^{3+}$ are the best candidates because of their long-lived intermediate energy states and because it is convenient to move them from the excitation of their intermediate state to the higher state. When used in combination with $\mathrm{Yb}^{3+}$ ions, they produce relatively high UCL efficiencies, as is the case with the currently popular $\mathrm{NaYF}_{4}: \mathrm{Yb}, \mathrm{Er} / \mathrm{Tm}, \mathrm{NaYF}_{4}: \mathrm{Yb}$ 
and $\mathrm{Er} / \mathrm{Tm}$, used as host matrix, sensitizer and activator, respectively [47].

Sensitized ions (such as $\mathrm{Yb}^{3+}$ ) usually maintain only one excited $4 \mathrm{f}$ state. The electronic transition energy in the energy states of individual $\mathrm{f}-\mathrm{f}$ state resonated with $980 \mathrm{~nm}$ radiation [48]. The energy gap in this transition overlaps strongly with many of the $\mathrm{f}-\mathrm{f}$ electron transitions to the lanthanide activator ions used in the UC system, and then the efficient fluorescence resonance energy transferred will happen [49]. For instance, following the activation of $\mathrm{Yb}^{3+}$, an energy transfer from $\mathrm{Yb}^{3+}$ to activators (such as $\mathrm{Er}^{3+}$ and $\mathrm{Tm}^{3+}$ ) occurs, the energy transfer processes for $\mathrm{Yb}^{3+}-\mathrm{Er}^{3+}$ and $\mathrm{Yb}^{3+}-\mathrm{Tm}^{3+}$ systems are illustrated in Fig. 2. The UC luminescence process of $\mathrm{Er}^{3+}$-activated $\mathrm{Yb}^{3+}$ can be divided into three parts: first, the conversion of the ground state ${ }^{2} \mathrm{~F}_{7 / 2}$ to ${ }^{2} \mathrm{~F}_{5 / 2}$ of $\mathrm{Yb}^{3+}$, followed by the transfer of the $\mathrm{f}-\mathrm{f}$ state photon energy to the ${ }^{4} \mathrm{~S}_{3 / 2}{ }^{2} \mathrm{H}_{11 / 2}$, and ${ }^{4} \mathrm{~F}_{9 / 2}$ to ground state ${ }^{4} \mathrm{I}_{15 / 2}$, to induce upconversion emissions at 658, 541, $522 \mathrm{~nm}$, respectively. Similarly, the $\mathrm{Yb}^{3+}-\mathrm{Tm}^{3+}$ system emissions at 800,650 , 474 and $450 \mathrm{~nm}$ correspond to the radiative transitions from ${ }^{3} \mathrm{H}_{4}-{ }^{3} \mathrm{H}_{6},{ }^{1} \mathrm{G}_{4}-{ }^{3} \mathrm{~F}_{4},{ }^{1} \mathrm{G}_{4}-{ }^{3} \mathrm{H}_{6},{ }^{1} \mathrm{D}_{2}-{ }^{3} \mathrm{~F}_{4}$, respectively [50].

\section{Mechanism}

Abundant energy states of lanthanide-based ions endow the upconversion nanoparticles with enormous chances for the up-energy transfer processes. These complex energy transfer systems can be divided into three processes: the excited-state absorption (ESA), energy transfer upconversion (ETU), and photon avalanche (PA) [56-58]. The fluorescence mechanism of UCNPs based on the principle of the two-photon or multiphoton process of UCL is illustrated in Fig. 3.
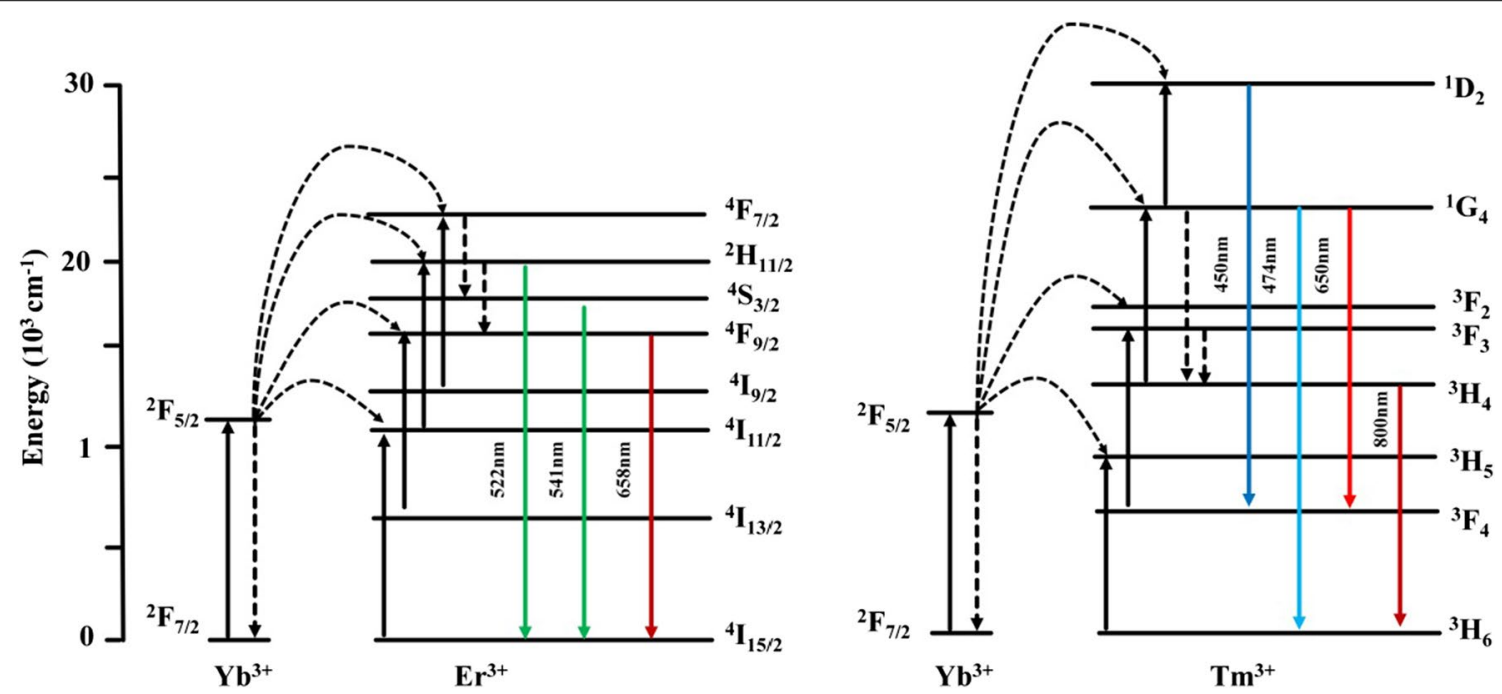

Fig. 2 Upconversion energy transfer mechanism based on $\mathrm{Yb}^{3+}$ and $\mathrm{Er}^{3+}$, and on $\mathrm{Yb}^{3+}$ and $\mathrm{Tm}^{3+}$ under $980 \mathrm{~nm}$ excitation

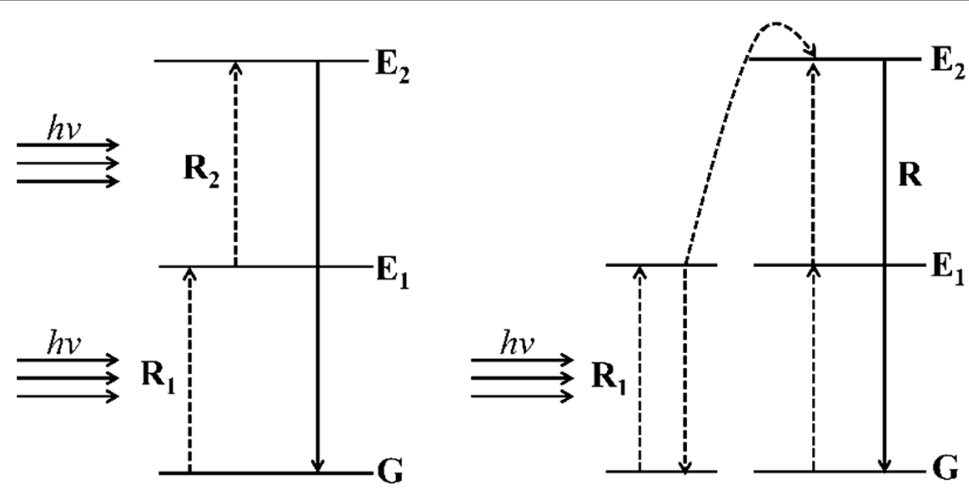

ESA

ETU

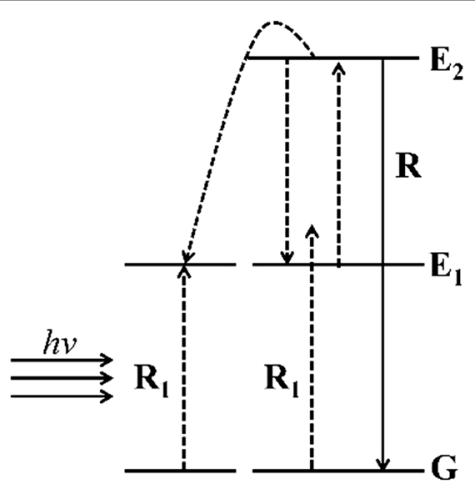

PA

Fig. 3 Main upconversion processes of doped UCNP 
Bloem et al. proposed that the excited-state absorption process in ESA is based on the principle that the same ion reaches the higher-energy excited-state energy level from the ground state $(G)$ through continuous multiphoton absorption, which is the most basic UCL process $[59,60]$. A photon of the luminescence center of the ground level $\mathrm{G}$ absorbs a photon transition to an intermediate metastable level $E_{1}$ which the vibration energy of the photon exactly matches the energy interval of the intermediate metastable level, and the higher excited-state level the ion at the metastable intermediate level jumps to a higher excited-state level $E_{2}$ by absorption of the photon energy to form a two-photon absorption. Moreover, if the energy matching requirement is satisfied, the ion at the excited state level is also likely to undergo higher excited states transition to form three-photon or four-photon absorption [61].

The energy transfer from the ETU process is a form of UCL that occurs when the same or different types of ions interact. The principle of luminescence is that the energy difference between the excited-state and the initial state of energy of the sensitized ion and the activating ion is the same and that when the distance between them is close enough, the electrons in the activating ion jump to a higher excited-state energy level, and resonance can occur between the two and produce energy, which is called energy transfer [62]. There are three main modes of ETU delivery: continuous energy transfer, cross-relaxation and cooperative upconversion.

The PA-based upconversion process is divided into three main steps [63]. First, an electron in ground state ions reaches the $\mathrm{E}_{1}$ level of the excited state through nonresonant ground state absorption and then reaches the higher energy level $E_{2}$ through the resonance excitedstate absorption process. Finally, the level $E_{2}$ interacts with the neighboring ground state, and the ions undergo cross-relaxation of energy transfer (or ion relaxation process), which results in two ions reaching the intermediate level $E_{1}$. This iteration eventually leads to an exponential increase in the number of electrons at the $\mathrm{E}_{2}$ level over time.

\section{Synthesis and functionalization of upconversion nanomaterial \\ Synthesis of UCNP}

A plethora of synthetic methods have been developed to prepare lanthanide-doped UCNPs. Because monodispersed nanoparticles smaller than $100 \mathrm{~nm}$ usually exhibit good biological performance for biomedical applications, the most commonly used methods for synthesizing UCNP nanoparticles are hydrothermal/solvothermal synthesis, sol-gel methods, and ionic liquid-based methods (Table 2) [64, 65]. Herein, we briefly introduce four representative methods which have been utilized to synthesize UCNPs with uniformly controllable size and high UCL efficiency.

\section{Thermal decomposition method}

The thermal decomposition method is a top-down method that is improved based on the traditional solvothermal method $[28,66,67]$. The main process is to first prepare the organometallic complex, then dissolve it in an organic solvent added with a stable surfactant, and short-term high-temperature thermal decomposition under the protection of the atmosphere, finally prepare the target product. Xie et al. introduced a high-temperature thermal decomposition method to prepare controllable $\mathrm{Nd}^{3+}$-doped UCNPs [44]. The results confirmed the feasibility of using $\mathrm{Nd}^{3+}$-sensitized core-shell nanoparticles, and the prepared nanoparticles have the same up-conversion characteristics as $\mathrm{Yb}^{3+}$-doped UCNPs. UCNP synthesized by the thermal decomposition method can also be applied to multi-functional application platforms. He et al. prepared UCNP with excellent emission wavelength by thermal decomposition method and loaded with photosensitizer for photodynamic therapy of three-dimensional (3D) HeLa cell spheroids [68]. The multifunctional PDT platform has been evaluated to confirm the feasibility of widely biomedical applications.

Table 2 Main synthetic method of UCNP and advantages and disadvantages

\begin{tabular}{|c|c|c|c|c|}
\hline Main synthetic method & Examples and refs & Size range $(\mathrm{nm})$ & Advantages & Disadvantages \\
\hline Thermal decomposition method & $\begin{array}{l}\mathrm{NaNdF}_{4}[44] \\
\beta_{-\mathrm{NaErF}_{4}[68]}\end{array}$ & $50-500$ & High-quality, uniform size & Intermediate toxicity, high cost \\
\hline Microemulsion method & $\begin{array}{l}\mathrm{LaF}_{3}[99] \\
\mathrm{NaYF}_{4}[85]\end{array}$ & $40-500$ & $\begin{array}{l}\text { Easy to operate, narrow size, high } \\
\text { stability, }\end{array}$ & $\begin{array}{l}\text { Calcination or annealing usually } \\
\text { required }\end{array}$ \\
\hline $\begin{array}{l}\text { Phase transfer hydrothermal } \\
\text { synthesis }\end{array}$ & $\begin{array}{l}(\mathrm{La}-\mathrm{Dy}) \mathrm{VO}_{4}[100] \\
\mathrm{YVO}_{4}[100], \mathrm{NaYF}_{4} \\
\text { [64], }\end{array}$ & $10-1000$ & $\begin{array}{l}\text { Good dispersion, simple proce- } \\
\text { dures, tunable size }\end{array}$ & $\begin{array}{l}\text { Specialized reaction vessels are } \\
\text { needed }\end{array}$ \\
\hline Sol-gel processing & $\mathrm{GdVO}_{4}[101]^{01}$ & $30-600$ & $\begin{array}{l}\text { Cheap raw materials, simple } \\
\text { procedures }\end{array}$ & $\begin{array}{l}\text { Broad particle size and unsuitable } \\
\text { for bioapplication }\end{array}$ \\
\hline
\end{tabular}


Similarly, Martinez et al. used methanol-assisted thermal decomposition to synthesized highly monodisperse $808 \mathrm{~nm}$ excited UCNP, which was tested in vitro PDT treatment [69]. The results explain that UCNP also has excellent colloidal stability and ROS activity in complex biological media. Although the thermal decomposition method can obtain high-quality UCNP with uniform particle size and monodisperse, its preparation precursor has the disadvantages of instability, toxicity, and high preparation cost and soon.

\section{Phase transfer hydrothermal synthesis}

Hydrothermal synthesis provides a cheaper and simpler method for the preparation of UCNPs for biomedical applications [70]. In the preparation stage of hydrothermal synthesis, various types of surfactants and ligands can be added to realize the functionalization of UCNP [71]. Phase transfer hydrothermal synthesis is an emerging synthetic method for the preparation of inorganic materials based on traditional hydrothermal synthesis. The entire reaction process requires high temperature and closed reaction vessel conditions [72, 73], and the solution show a variety of excellent advantages for preparing lanthanide-based UCNPs at room temperature, such as increased of solubility and ion activity [74, 75]. $\mathrm{Li}$ et al. provided a detailed description of such carboxylic acids and inorganic metals transfer phase alkylation reaction system based on the thermal brine synthesis mechanism (Fig. 4): first, the lanthanide metal salt-containing heavy metal ions added into the solid phase down to exchange $\mathrm{Na}^{+}$to form an alkyl; the ion exchange process of the chain carboxylic acid complex is then reduced

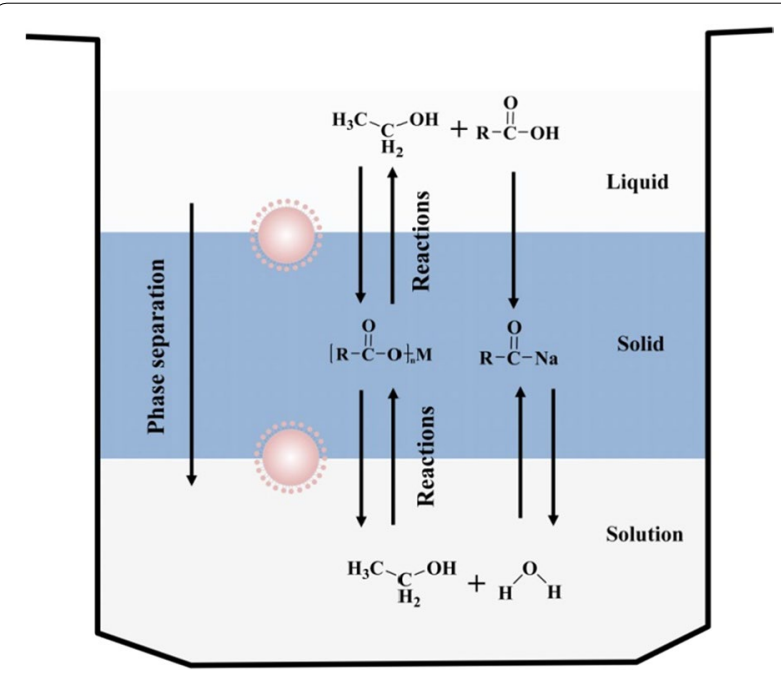

Fig. 4 Diagram of the liquid-solid-solution phase transfer hydrothermal synthesis mechanism at the liquid-solid or solution-solid phase interface; and the periphery of the nanoparticle is always surrounded by an alkyl chain to form a hydrophobic outer structure [76]. When the nanoparticles grow to a suitable size, they settle down due to the action of gravity, so that the nanoparticles can be collected at the bottom. This method provides more phase selection than traditional preparation processes, and by adjusting the reaction system factors, such as temperature, $\mathrm{pH}$, and processing time, the synthesis of UCNPs can be controlled. Zhang et al. reported the hydrothermal synthesis of $\mathrm{NaYF}_{4}$ nanorods, nanotubes, and flower-like nanodisks in a three-phase solution of ethanol, oleic acid and water [77]. By adjusting the $\mathrm{pH}$ value of the system, nanosheets, nanowires and the crystal structure of the nanorods were formed; they also found that nanocrystals are more fluorescent in polar solvents than in nonpolar solvents. Li's group used oleic acid to synthesize UCNP in aqueous solution, and then added cyclodextrin into the system to make the nanoparticles hydrophilic and soluble, which enables them to carry hydrophobic drugs and dyes [78]. Zhang et al. designed a novel NIR photoactivated photosensitizer based on $\mathrm{TiO}_{2}$ coated UCNP core/shell nanocomposites (UCNPs@ $\mathrm{TiO}_{2}$ $\mathrm{NCs}$ ) by using water phase transfer to synthesize UCNPs (Fig. 5). $\mathrm{NaYF}_{4}: \mathrm{Yb}^{3+}, \mathrm{Tm}^{3+} @ \mathrm{NaGdF}_{4}: \mathrm{Yb}^{3+}$ core/shell UCNPs can effectively convert NIR light into UV emission, which is matched with the absorption of the $\mathrm{TiO}_{2}$ shell [79]. However, this method of producing nanoparticles is inefficient and time-consuming, and the synthesis process is difficult to control and costly. A great deal of effort has been put into new approaches to synthesizing UCNPs to make the process faster, cheaper, and more efficient, not only for fundamental research, but also for high-tech applications.

\section{Microemulsion method}

Microemulsion template synthesis refers to the surfactants and raw material involved in the template synthesis method, which uses several aggregated forms obtained after aggregation, such as micelles, vesicles, liquid crystals, and microemulsions, which form a microreactor with a size in the nanometer range [8082]. The size and internal state of the droplet reactor determine the basic properties of the nanoparticle, and due to the morphological controllability of surfactant soft aggregates, the controllable nanoparticles can be better achieved [83, 84]. A successful example has been reported: UCNP wrapped in ethylenimine polymer synthesized by this method can be used as advanced fluorescent probes to detect $\mathrm{Pb}^{2+}$ through the fluorescence quenching process generated by electrostatic interaction with the polymer [85]. Yang et al. combined synthetic UCNPs with carbon nanotubes 

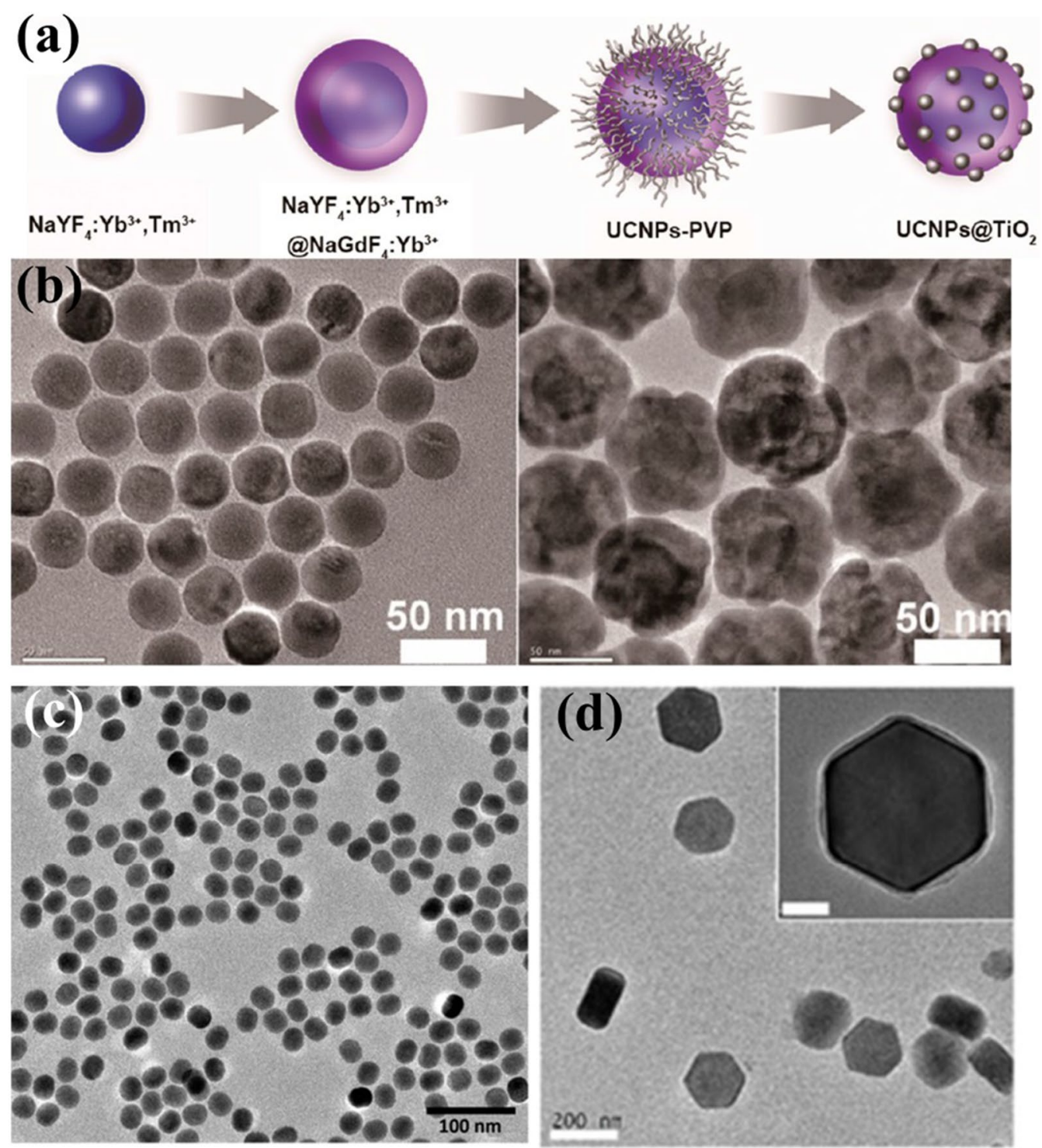

Fig. 5 a Schematic illustration of the hydrothermal preparation synthetic procedure of UCNPs@TiO $\mathrm{NCs}_{2}$ 79]. b TEM images of the original $\mathrm{NaYF}_{4}: \mathrm{Yb}^{3+}, \mathrm{Tm}^{3+}$ cores (scale bar $=50 \mathrm{~nm}$ ). $\mathbf{c}$ Sol-gel method for synthesized 2-aminoethyl dihydrogen phosphate-stabilized $\mathrm{NaYF}_{4}: \mathrm{Yb}^{3+}, \mathrm{Er}^{3+}$ nanoparticles (scale bar: 100 nm) [97].d UPP@ovalbumin were prepared by microemulsion synthesis [98]. (Copyright 2015, 2012 and 2015. American Chemical Society. Reproduced with permission.)

using surfactants, and further therapeutic effects are evident in genomic DNA damage and the cell cycle [86]. Therefore, the prepared nanoparticles interface had high stability and good dispersion compared with other methods, the addition of surfactant molecules can not only control the size, but also modify the surface of the nanoparticles [87, 88]. However, the microemulsion method needs to remove the surfactant after preparing the nanoparticles. Compared with other methods, the yield of this method is reduced by
$20-40 \%$ [40], and the nanoparticles have weakened monodispersity, so this method is suitable only for laboratory research [89].

\section{Sol-gel method}

The sol-gel method generally uses a metal-organic or inorganic solution as the base solution in low temperature solution to prepared inorganic materials or composite materials [90-92]. This method has the unique advantages of uniform mixing of reactants, easy doping 
of trace elements and low reaction temperature. On this basis, a large number of studies on temperature characteristics of UCNPs have been performed. Peng et al. [93] used the sol-gel method to prepare lanthanide co-doped $\mathrm{Na}_{0.5} \mathrm{Gd}_{0.5} \mathrm{MoO}_{4}$ phosphors and evaluated them as optical temperature sensors and optical heaters for potential applications. Tang et al. used this method to synthesize $\mathrm{La}, \mathrm{Gd}$, and $\mathrm{Lu}$ nanocrystals doped with $\mathrm{Yb}^{3+}$ and $\mathrm{Er}^{3+}$, and compared the temperature-dependent UC behavior and optical temperature sensing characteristics of the fluorescence intensity ratio of these nanocrystals [94, 95]. Prasad et al. prepared a $\mathrm{ZrO}_{2}$ : Er UCNP based on $\mathrm{ZrO}_{2}, \mathrm{TiO}_{2}: \mathrm{Er}, \mathrm{BaTiO}_{3}: \mathrm{Er}, \mathrm{Lu}_{3} \mathrm{Ga}_{5} \mathrm{O}_{12}:$ Er and $\mathrm{YVO}_{4}: \mathrm{Yb} /$ Er using an improved sol-gel method [96]. However, it is difficult to achieve the desired UCNP particle size and dispersion level using this method, which impacts the surface modification of the nanomaterial and limits its application in biomedicine.

\section{Functional modification}

Usually, subsequent surface modification of nanoparticles is necessary to yield a surface composition suitable for biomedical applications [102]. For example, by changing UCNPs surface ligands to load some hydrophobic drugs, surface charge to adsorb small molecules, and even in combination with some biomolecules for bioimaging and therapeutic applications [103]. Nevertheless, different needs create different modifications, and careful design and optimization of these aspects are essential before UCNPs can be used for bioanalytical applications. A variety of surface modification studies have been reported; we divide the functional modifications into three categories (in Fig. 6): hydrophilic modification, bioconjugation, and hybrid materials [104].

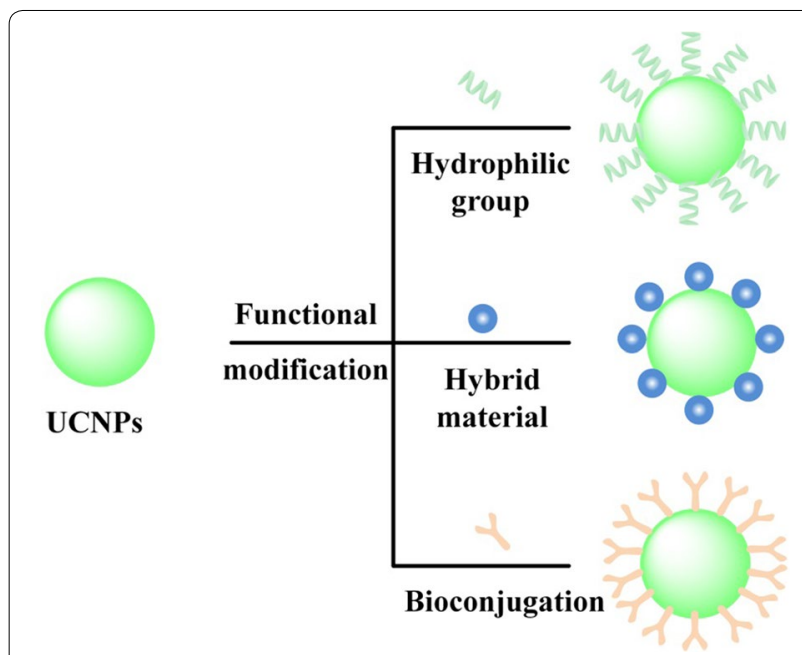

Fig. 6 Commonly used methods of functionalizing UCNPS

\section{Hydrophilic modification}

The nanoparticle dispersion in an aqueous medium must be stable under long-term preservation to avoid aggregation and precipitation during storage or application [105]. The initially synthesized UCNPs are easily covered by hydrophobic ligands, which directly lead to the inability of UCNPs to form stable water-dispersion systems [106]. In fact, organic solvents have higher phonon energy and energy transitions than water. However, the transfer to an organic solvent leads to fluorescence quenching, and surface hydrophilic modification of UCNPs seems imperative [107]. Methods for producing hydrophilic modifications usually involve adding (1) acidic ligands [108] (2) polymers [109] or (3) chelating agents [110], and these ligands usually have hydrophilic functional groups, such as a hydroxyl group, primary or secondary amine, and carboxylic acid, etc. When citrate acid is used as a growth control agent in hydrothermal synthesis, the resulting UCNP's shape and size can be controlled and evenly dispersed in aqueous solution by adjusting the ratio [111]. Ethylenediaminetetraacetic acid, which has a high chelating constant for all lanthanide-based ions, and coordinated surface by chelation to stabilize the lanthanide ions in the solution $[112,113]$. Because of the presence of primary, secondary and tertiary amino groups of polymers, polyethyleneimine (PEI) can easily coordinate with the lanthanide ions, thereby transforming the growth of the nanoparticles and obtaining pro-aqueous UCNPs [113]. Lai et al. described a hydrophilic functionalization of a zinc-diamine analog (TDPA- $\mathrm{Zn}^{2+}$ ) on the surface of UCNPs (Fig. 7) and the loading of small-molecule drugs or chemotherapeutic agents in the internal mesopores [114].

\section{Bioconjugation}

Nanomaterials can be used in bioanalytical applications by modifying specifically identified biomolecules. Table 3 presents some biomolecules which can be used as specific recognition elements of UCNPs through preferential surface modification. Many biomolecules, such as streptavidin, are negatively charged proteins that can easily coordinate with UCNP surfaces but cause nanoparticle aggregation. Kamimura et al. reduced the nonspecific binding by co-simulating PEG-b-PAA and streptavidin on the surface of the UCNP, and usually, in the four binding sites of streptavidin, at least one of them could be used for biotin binding [115]. Recent research has found that the surface-modified ligand on UCNPs can be converted to a new functional group to affect the subsequent bioconjugation step. Ligands commonly used for attachment are maleimides [98], thiols [116], carboxylic acids [117], aldehydes, and amine groups. Figure 8 showed a typical bioconjugation process, which uses a typical 

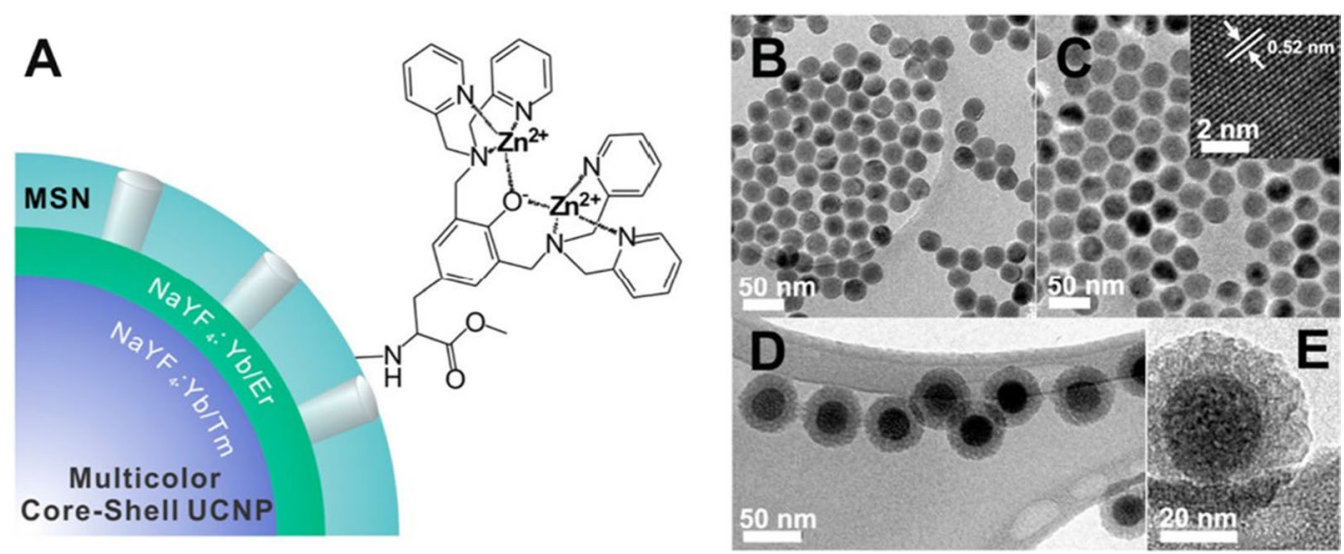

Fig. 7 a Hydrophilic modification structural illustration of a multicolor core/shell UCNP, b-e TEM images of the UCNP before the growth of $\mathrm{NaYF}_{4} \mathrm{Yb}^{3+} / \mathrm{Er}^{3+}$ shell core and after functionalization of $\mathrm{NaYF}_{4}: \mathrm{Yb}^{3+} / \mathrm{Er}^{3+}$ with zinc-dipicolylamine analog (TDPA-Zn ${ }^{2+}$ ) and MSNs [114]. ( Copyright 2015. American Chemical Society. Reproduced with permission.)

Table 3 UCNP modified by biomolecules in biomedical applications

\begin{tabular}{|c|c|c|}
\hline Biomolecule & Examples and refs & Application \\
\hline \multirow[t]{2}{*}{ Antibody } & $\mathrm{NaYF}_{4}: \mathrm{Yb}, \mathrm{Er}[130]$ & LRET system \\
\hline & $\mathrm{NaYF}_{4}: \mathrm{Yb}, \mathrm{Er}[131]$ & Photodynamic therapy \\
\hline \multirow[t]{2}{*}{ DNA/RNA/MiRNA } & $\mathrm{NaYbF}_{4}: \mathrm{Yb}, \mathrm{Er}$ [109] & $\begin{array}{l}\text { Delivery and transfection } \\
\text { of siRNA }\end{array}$ \\
\hline & $\mathrm{NaYF}_{4}: \mathrm{Yb}, \mathrm{Tm}[108]$ & Specific binding site \\
\hline \multirow[t]{2}{*}{ Protein/peptide } & $\mathrm{NaYF}_{4}: \mathrm{Yb}, \mathrm{Er}[132]$ & In vivo imaging \\
\hline & $\mathrm{NaYF}_{4}: \mathrm{Yb}, \mathrm{Tm}[110]$ & Proof of principle \\
\hline Folic acid & $\mathrm{NaYF}_{4}: \mathrm{Yb}, \mathrm{Er}$ [133] & Tumor targeting/imaging \\
\hline Avidin & $\begin{array}{l}\mathrm{NaYF}_{4}: \mathrm{Yb}_{1} \mathrm{Er} / \\
\mathrm{NaYF}_{4} \mathrm{Yb}, \mathrm{Tm} \text { [134] }\end{array}$ & Assay application \\
\hline
\end{tabular}

amide reaction to achieve the function of engineering a specific protein on the surface of UCLNP [118]. On the other hand, the amine group of the UCNP can be converted into a carboxyl group by a ring-opening reaction of succinic anhydride or glutaric anhydride, and the exposed carboxyl group can then be activated by forming an $\mathrm{N}$-hydroxysuccinimide ester to realize the purpose of the combination $[119,120]$.

\section{Hybrid materials}

The combination of UCNPs with other nanomaterials can formation hybrid materials for the multifunctional applications. In some specific circumstances, the hybrid materials can not only enhance UCL, but also own the characteristics of materials. UCNPs can also be doped with paramagnetic agents such as $\mathrm{Gd}^{3+}$, especially in combination with superparamagnetic $\mathrm{Fe}_{3} \mathrm{O}_{4}$ nanoparticles, which can be applied to multifunctional biomedical platforms. As shown in Fig. 9, the synthetic process of magnetic UCNPs was prepared by EDC/NHS activation and the binding of UCNP surface affinity to $\mathrm{Fe}_{3} \mathrm{O}_{4}$ nanoparticles [120]. The hybrid nanomaterials make a difference in the separation and purification of biomolecules or the design of multimodal bioimaging probes. Noble metals such as a silver shell modified on the surface of UCNPs can enhance UCL efficiency by surface plasmon coupled emission to produce a multimodal hybrid material, which can be used for photothermal therapy [121]. By adjusting the thickness of the silver layer, the wavelength of the UCNP surface plasmon resonance can be adjusted to $980 \mathrm{~nm}$, and bioimaging by upconversion emission can be performed simultaneously under single wavelength illumination [122]. Similarly to the magnetite nanoparticle modification method, silver nanoparticles occupy the thiol group on the surface of the UCNP for nucleation behavior.

\section{Upconversion nanomaterials for biomedical applications}

The morphology and size of nanoparticles (NPs) result in (1) prolongation of the blood's circulation time and (2) low endotoxin, which can be absorbed and cleared in the cells by endocytosis. Thus, NPs with a small molecular size can be used as a powerful tool for biomedical research and clinical diagnosis and treatment. UCNPs have been adopted in a wide range of biomedical applications, due to their unique NIR excitation, high luminescence stability, and high detection sensitivity, especially in biosensor, bioimaging, and disease treatment. In biosensing applications, UCNPs can be used in the detection of infectious bacteria, pathogens, and viruses in food residues, especially UCNPs have been extensively studied in immunochromatographic assays, which is one 


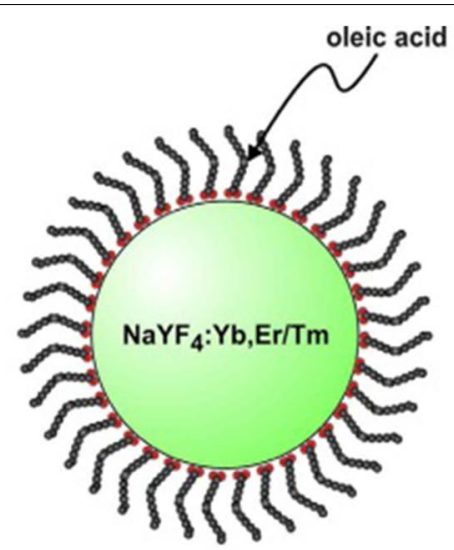

hydrophobic UCLNP

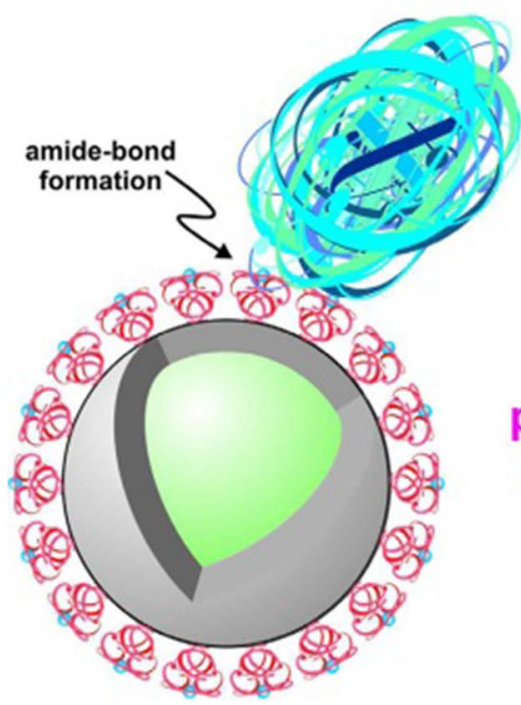

protein-UCLNP-conjugate

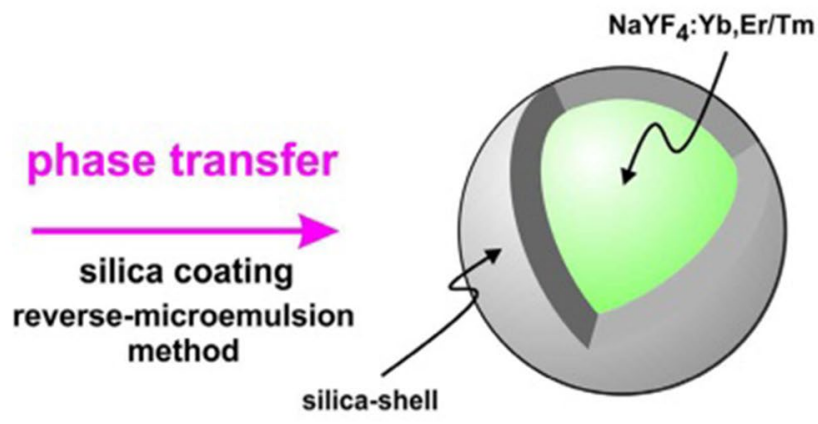

hydrophilic UCLNP

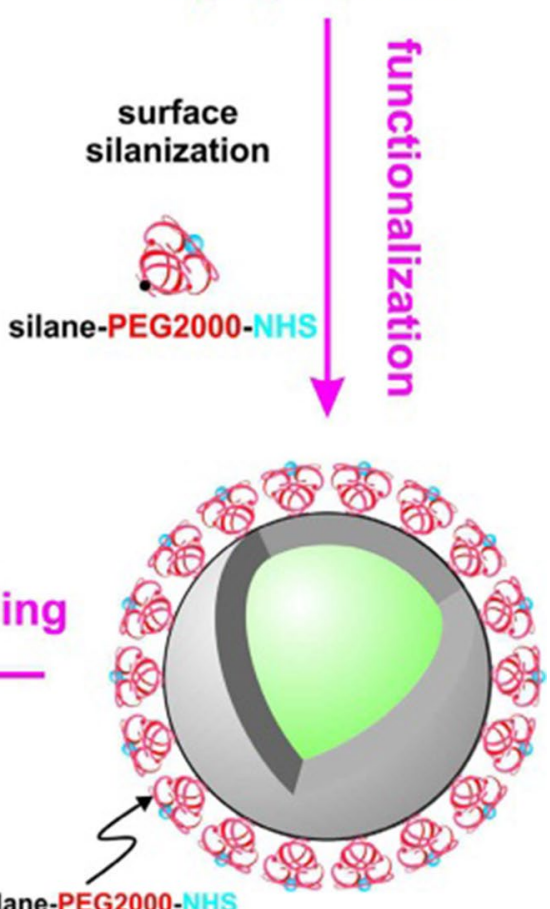

protein-reactive UCLNP

Fig. 8 Surface engineering of a UCLNP towards protein-reactive, multicolor upconverting labels

of the best devices for instant diagnosis [123-125]. Figure 10 illustrates the use of UCNPs as energy donors and the subsequent selection of appropriate energy receptors to achieve the detection of targets through luminescence resonance energy transfer (LRET), which has been applied extensively in early disease diagnosis [126]. Li's group initiated the research on the FRET phenomenon, which is based on UCNPs designed for biological detection [127]. The biotin-modified UCNPs and gold nanoparticles form an energy-donor-acceptor system, when UCNPs are attached to gold NPs; the UCNPs will undergo a quenching effect. Subsequently, with the increased number of Au NPs on the UCNP surface, the quenching may become increasingly intense, so that the concentration of avidin can be detected with a limit of $0.5 \mathrm{nM}$. In addition to the above biosensing applications, lanthanide-based UCNPs have also been used as imaging agents and therapeutic carriers, with great potential for biomedical applications $[128,129]$. 


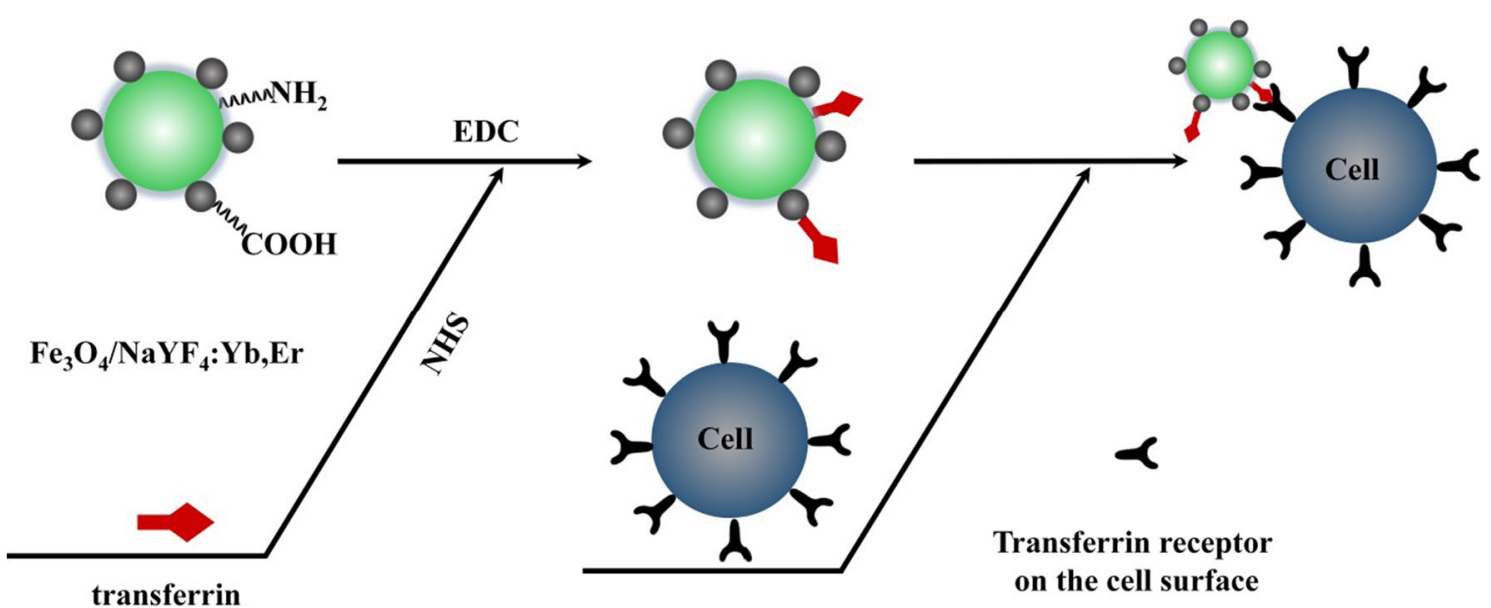

Fig. 9 Schematic diagram of the chemical coupling method to combine $\mathrm{Fe}_{3} \mathrm{O}_{4}$ with $\mathrm{NaYF}_{4}$ nanomaterials for biomarker HeLa cells [120]. ( Copyright 2010. The National Center for Biotechnology Information. Reproduced with permission.)

\section{Biological imaging}

Bioimaging probes are usually composed of organic fluorophores or fluorescent proteins, but they produce strong background fluorescence in the visible light region and have poor light stability, which greatly limits their biomedical applications [135-137]. Quantum dots (QDs) have high photostability, it is difficult to make extensive use of them in vivo due to their toxicity and side effects. In contrast, lanthanide-based UCNPs have unique advantages, such as stable chemical properties, high-intensity light emission efficiency, deep penetration, and no background fluorescence, which make them an ideal biomarker for transcending organic fluorescence and QDs [138]. UCNPs can emit visible light

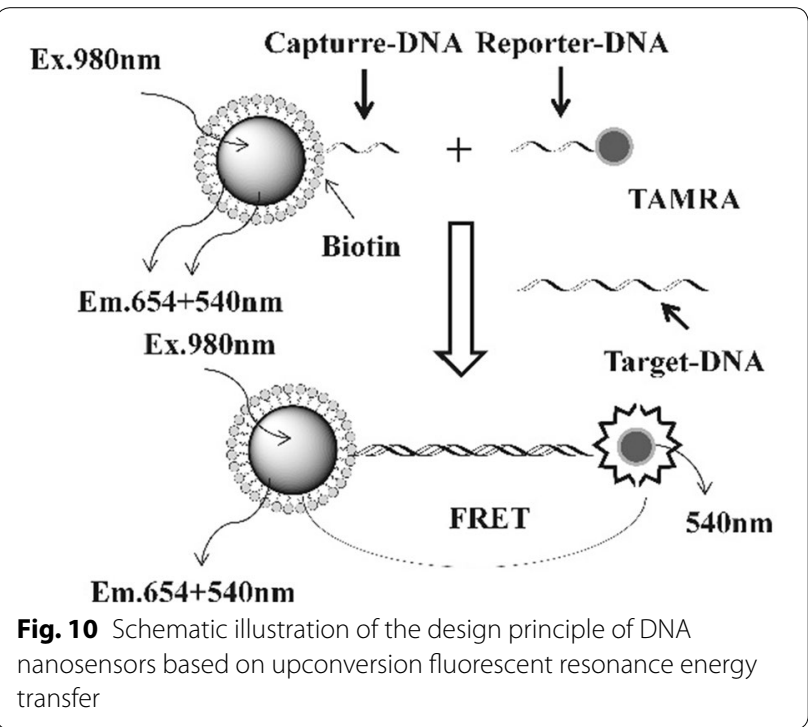

under the excitation of NIR, which can avoid the tissue damage caused by the excitation light, and the application of the NIR excitation light increases the photon's penetration limit in tissues.

\section{Upconversion luminescence imaging}

UCL bioimaging is based primarily on visible (red, green or blue) emissions from $\mathrm{Er} / \mathrm{Ho} / \mathrm{Tm}$ doped UCNP, and the emission spectrum ranges cover from blue to green fluorescence [139]. In the spectral range of 400-700 nm, cells have a strong absorption band and are therefore often used to monitor single molecules and growth processes in living cells. The work of Chatterjee et al. included the use of PEI-coated $\mathrm{NaYF}_{4}: \mathrm{Yb}$, Er for cancer cell imaging. Moreover, strong green UCL could be observed on the cell membrane by fluorescence observation under NIR excitation [140]. Early NIR to visible UCL bioimaging was difficult to achieve the visible millimeters of tissue penetration depth. However, Zhao and colleagues demonstrated UCL imaging with considerable tissue depth using $\mathrm{NaYF}_{4}: \mathrm{Yb}, \mathrm{Er}$ NPs as a luminescent probe for nude mice achieving a penetration depth of $1 \mathrm{~cm}$ for the first time [141]. In addition, Liu and colleagues compared UCL imaging of pork muscle tissues at different depths $(0-1 \mathrm{~cm})$ by injection of polymer-modified $\mathrm{NaYF}_{4}: \mathrm{Yb}, \mathrm{Er}$ and $\mathrm{KMnF}_{3}: \mathrm{Yb}$, Er. For $\mathrm{NaYF}_{4}: \mathrm{Yb}$, Er the image can be detected at a depth of about $0.5 \mathrm{~cm}$, while $\mathrm{KMnF}_{3}$ has a very strong red emission which can sense a tissue depth of $1 \mathrm{~cm}$ [107]. In Xu et al's work (Fig. 11), antigen-loaded UCNPs were used to label and stimulate dendritic cells (DCs), and the UCNP-labeled DCs achieved high-sensitivity in vivo UCL imaging; finally, a strong antigenspecific immune response was induced by the successful postinjection of DC vaccines [98]. 


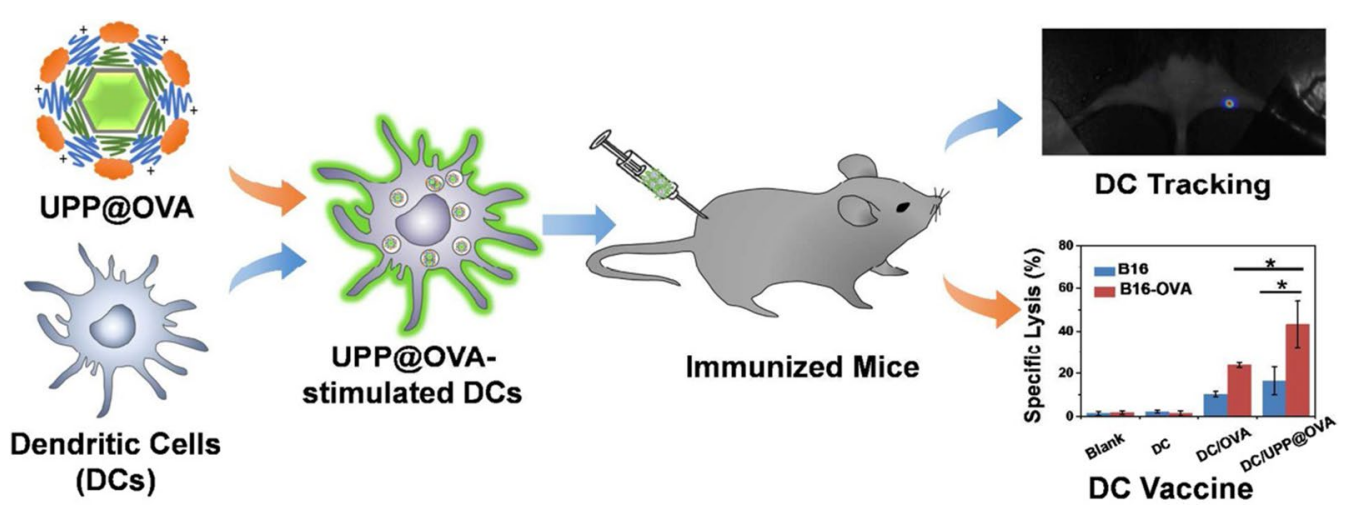

Fig. 11 Schematic illustration of antigen-loaded UCNPs for dendritic cell (DC) stimulation, tracking and vaccination in DC-based immunotherapy [98]. ( Copyright 2015. American Chemical Society. Reproduced with permission.)

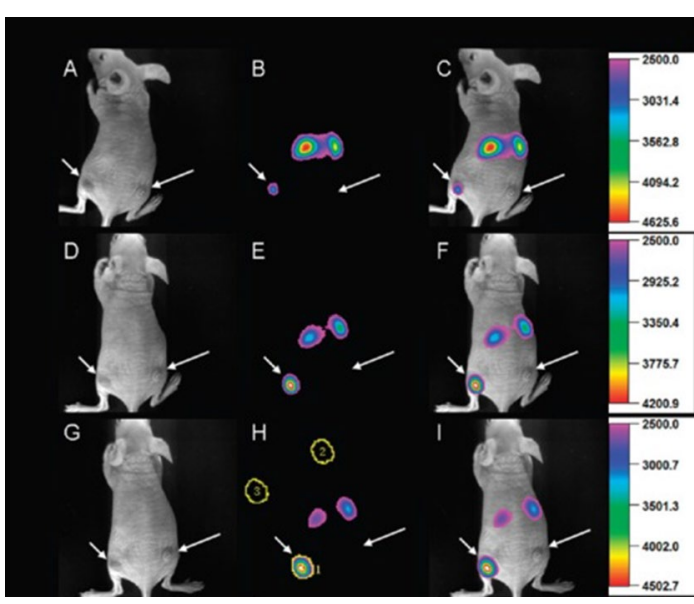

Fig. 12 Time-dependent in vivo upconversion luminescence imaging of subcutaneous U87MG tumor (left hind leg, indicated by short arrows) and MCF-7 tumor (right hind leg, indicated by long arrows) borne by athymic nude mice after intravenous injection of UCNP-RGD over a $24 \mathrm{~h}$ period [146]. ( Copyright 2009. American Chemical Society. Reproduced with permission.)

\section{Tumor targeting imaging}

Tumor targeting is a prerequisite for improving imaging and therapeutic efficacy; the targeting markers specialized for diseased areas are particularly excellent for cancer treatment that selectively kills cancer cells $[109,142$, 143]. Emerging targeting technology for the attachment of biomolecules to imaging agents provided high efficiency and low toxicity for molecular targeting. Due to the unique optical properties of UCNP, they are widely used in actively targeted imaging of tumors. Li and coworkers engineered a targeted imaging system based on RGD peptides and $\alpha v \beta 3$ integrin receptors (Fig. 12) [144]. They linked RGD peptides to the surface of UCNP to form UCNP-PEG-RGD and found that the nanoparticles could efficiently target U87MG tumors. A strong UCL signal was witnessed in the left hind leg excited by the excitation of $980 \mathrm{~nm}$; however, no noteworthy UCL signal was seen in the other legs. Achieving in vivo specific tumor imaging based on RGD peptide-protein recognition showed that UCNP can be used as molecularly targeted probes for the diagnosis of tumor tissue. Chen et al. [145] applied PEI-modified UCNP to cancer cell bioimaging; the synthesized $\mathrm{NaYF}_{4}: \mathrm{Yb}, \mathrm{Er}_{\mathrm{S}} \mathrm{SiO}_{2}$ nanocrystals were directly applied to MCF-7 cancer cells under $980 \mathrm{~nm}$ excitation, and the green luminescence in cells was performed by confocal microscopy.

\section{Multi-modality imaging}

To obtain accurate imaging information for clinical diagnosis and further practical processing, researchers have expanded imaging applications by introducing other functional components to form nanocomposites, in particular by combining the benefits of two or more nanoparticle imaging techniques to form multimodal biological imaging [147]. UCNP are excellent optical imaging probes and can be used as multimodal contrast agents for multimodal bioimaging, such as UCL/MRI, $\mathrm{UCL} / \mathrm{MRI} / \mathrm{CT}$, UCL/MRI/PET, UCL/CT and MRI/CT. Here, we highlight the imaging applications of UCL/ MRI. MRI is a medical diagnostic technology based on nuclear magnetic resonance (NMR); MRI and UCL imaging are two modes of coordination. When one system is combined with another, the advantages of high spatial resolution and sensitivity are combined to enhance the signal strength of bioimaging. NPs can be combined with UCNP to design bimodal UCL/MRI contrast agents, such as Gd-centered hosts and $\mathrm{NaGdF}_{4}$ [148], $\mathrm{Gd}_{2} \mathrm{O}_{3}$ [149], $\mathrm{GdF}_{3}[150]$ and $\mathrm{BaGdF}_{5}[151]$. Li and colleagues confirmed that $\mathrm{NaGdF}_{4}: \mathrm{Yb}, \mathrm{Er}, \mathrm{Tm}$-PAA NPs exhibited a high relaxation rate $\left(5.6 \mathrm{~s}^{-1} \mathrm{mM}^{-1}\right)$ and it was clear that the signal 

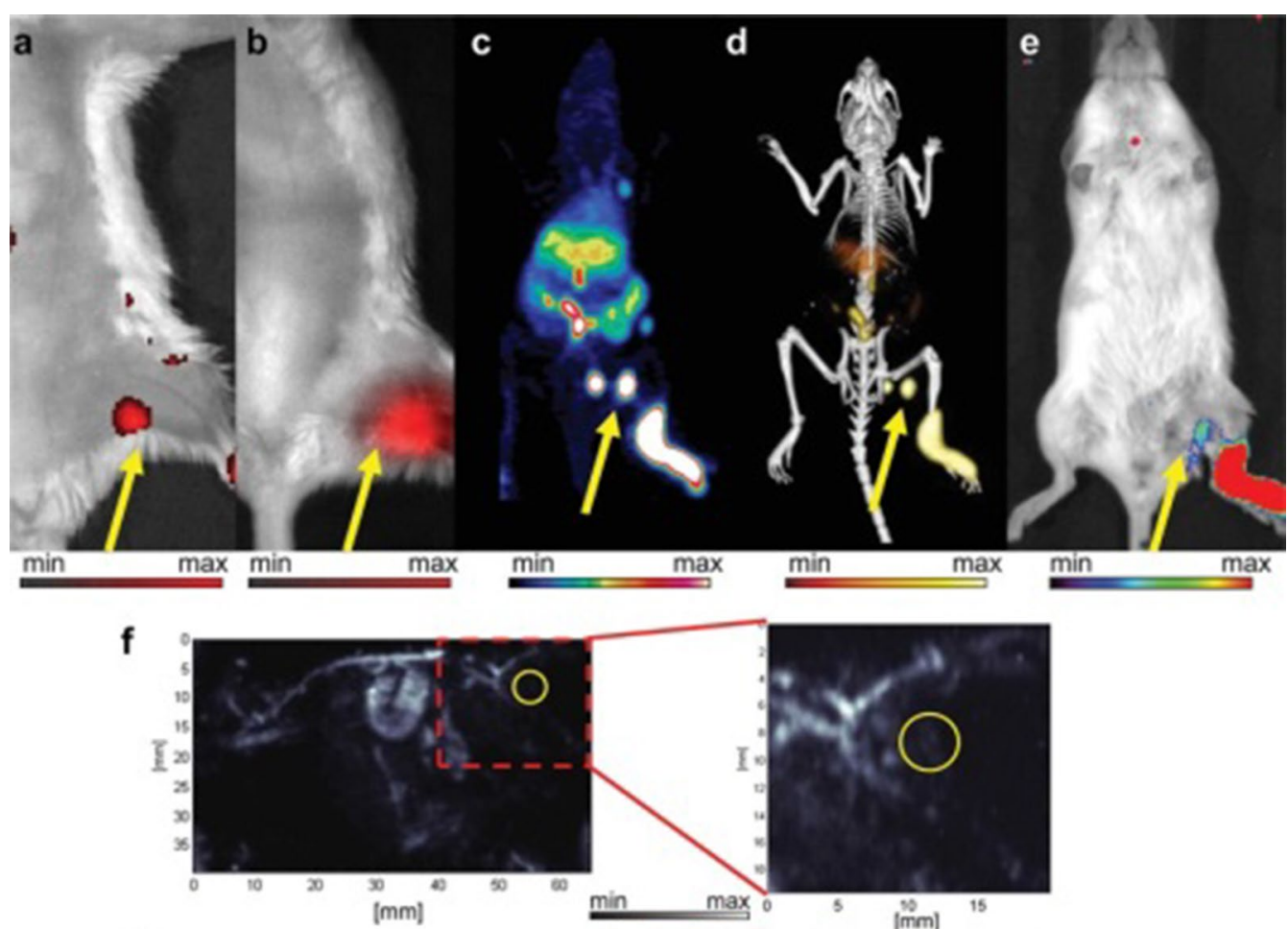

Fig. 13 In vivo lymphatic imaging using PoP-UCNPs in mice. a Traditional FL and $\mathbf{b} \cup C$ images c full anatomy PET, $\mathbf{d}$ merged PET/CT and e CL images and PA images f [153]. (Copyright 2015. Advanced Materials. Reproduced with permission)

enhancement of the UCNP in different organs after comparison [152]. James et al. studied in vivo lymphoid imaging of mice using PEG and chelated radioactive ${ }^{64} \mathrm{Cu}$ PoP lipid coated UCNP ( Fig. 13) which was found to exert an active influence in six different imaging modalities. More specifically, PET and CT provided the deepest tissue imaging capabilities, and CL and UC imaging could detect deeper signals for the previous FL [153]. In summary, UCNPs used for manufacturing simple but higher order multimodal imaging agents are feasible and can be used in the development of super-integrated imaging systems $[21,154]$.

\section{Therapeutics}

Scholars have explored how to shorten the gap between biomaterials and clinical treatment diagnosis. Therefore, the construction of a multifunctional nanomedicine platform for disease treatment has attracted their attention. To meet the needs of both disease diagnosis and in vivo treatment, varieties of UCNP-based nanocomposites have been used as drug delivery systems as well as drug monitoring devices.

\section{Drug delivery and release}

Compared with traditional medicine, UCNP-based drug delivery has obvious advantages such as small particle size, which facilitates the endocytosis of cells to obtain a good therapeutic effect [155-157]. The huge surface area of UCNP can prolong the retention of topical drugs and increase the utilization of drug targeting in the tissues $[158,159]$. Even better, UCNP-based composites used as drug delivery systems will enable tracking and efficiency evaluation of drug release in real-time [160, 161]. Researchers have prepared UCNP drug delivery for drug loading, and targeted modification of the delivery surface to release drug molecules and transport them into tumor cells [162]. Duan et al. grafted the target molecule folic acid (FA) onto the surface of PEI-modified UCNP and loaded with camptothecin (CPT)/doxorubicin (DOX) for the targeted cancer treatment at the first time [125]. Liu et al. constructed a multifunctional nanocarrier based on an oleic acid-blocked UCNP, which was loaded with DOX drugs by directly coating NIR-absorbed polydopamine (PDA) shells on the surface of UCNPs and provided five kinds of biological imaging. The function realized the synergistic inhibition effect of PTT and the chemotherapy effect on mouse colorectal SW620 tumors [163]. Lanthanide-based UCNPs can also be induced by 
a

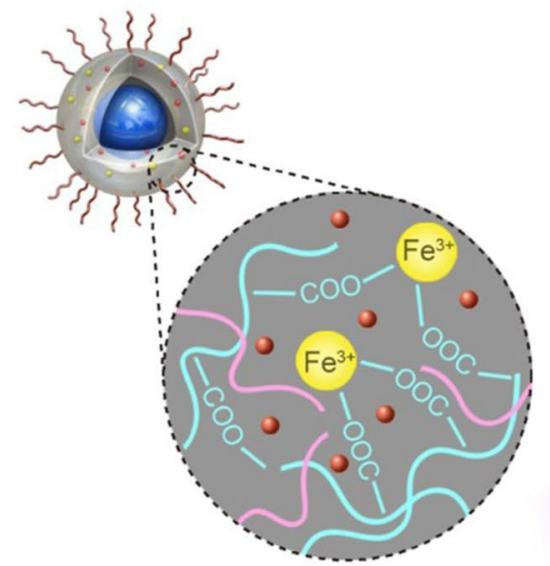

b
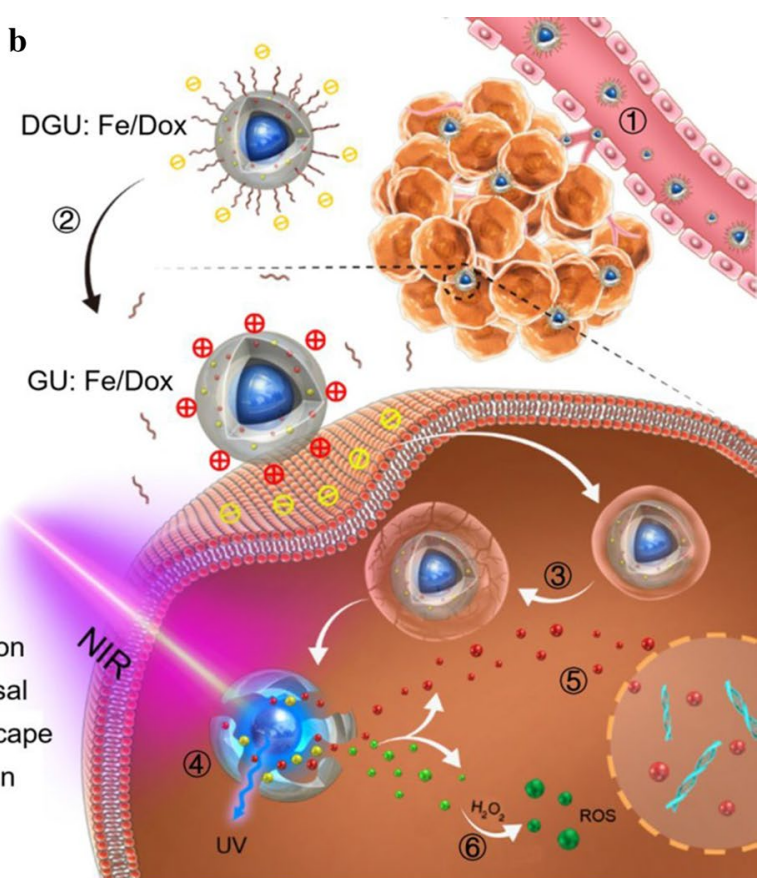

Fig. 14 UCNP and DOX were loaded into gel nanoparticles and modified with PEl and DMMA to construct a nanolongan schematic with multiple transformations and corresponding anticancer mechanisms. ( Copyright 2019. American Chemical Society. Reproduced with permission.)

NIR light to achieve drug and gene release therapy [164, 165]. Liu et al. constructed a nano-transport system that encapsulated UCNP and DOX in oxidized starch-based gel nanoparticles (Fig. 14); further, PEI and 2,3-dimethyl maleic anhydride (DMMA) were used to decorate them. The results show that multiple modifications can prolong the circulation time of the drug in the body and that the EPR effect provides more opportunities for the drug to reach the tumor site and achieve rapid release of the drug pair [166].

UCNPs used as drug delivery devices can achieve the conventional release process. Lin's group designed a controlled drug release system based on UCNPs that could accelerate drug release by changing $\mathrm{pH}$ or temperature conditions [65]. It is worth mentioning that the new lightcontrolled drug delivery process based on the structure of UCNPs has become a new research hotspot, in particular through the use of NIR-light-induced photo-controlled drug release [161, 167]. NIR-UV-based UCNPs were used for gene release: after $980 \mathrm{~nm}$ excitation, UCNP could release DNA and small interfering RNAs (siRNA) from UV light. The induced photo-controlled drug release inhibited the gene expression of tumor cells to achieve therapeutic effects [138].

\section{Gene delivery}

The key challenge of cancer gene therapy is achieving a precise strike of the therapeutic agents into the solid tumor site. One effective method for accomplishing this goal is to develop efficient gene delivery systems to improve the therapeutic index of drug molecules and minimize the toxic side effects on healthy cells and tissues. UCNPs have been reported to provide comprehensive transport of genes such as DNA and siRNA. The tricky problem of RNAi therapy is how to effectively protect the siRNA biomolecules from the complex physiological environment and how to increase the delivered expression effect. Yang's research team mounted siRNA on the surface of UCNPs in order to attach anti-Her2 antibodies [168, 169]. The release of siRNA could be monitored synchronously through the signal of energy resonance transfer. Xing et al. used UCNPs as energy transfer receptors through the FRET to control the release of luciferase. First, luciferase was encapsulated in a NIR-sensitive polymer, then through UCNPs to transfer the energy of luciferase to achieve the bioluminescence in the deep tissue of mice, which used for real-time imaging monitoring of tumor growth [144]. In the work of Liu et al., PEG-modified UCNPs were combined with terminal FA molecules and the chemotherapeutic drug DOX was incorporated into the surface of UCNPs through hydrophobic interaction to stimulate multifunctional 


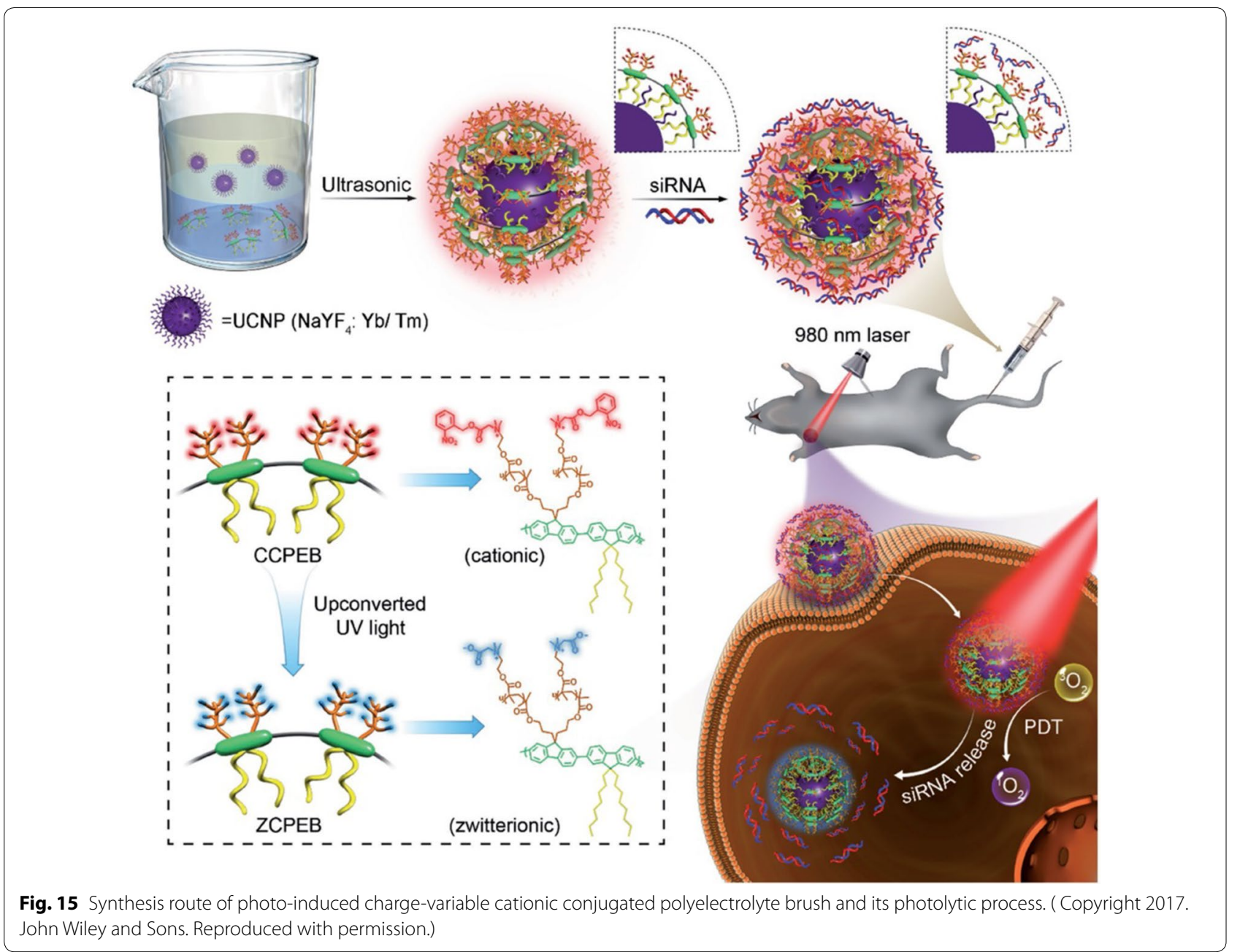

targeting and cell imaging [32, 170]. For some intractable diseases, the combination of PDT and gene therapy is often chosen. For example, Zhao et al. developed a photodynamic therapy strategy for a strongly positively charged cationic conjugated polyelectrolyte (CPE) combined with UCNPs. CPE can be used as a photosensitizer for PDT and nucleic acid carrier to load siRNA (in Fig. 15), which gives the prepared UCNP@(CPEB) good stability and excellent siRNA loading capacity. They concluded that the efficient siRNA release (80\%) and synergistic PDT treatment demonstrate suppressive effects on A549 tumors under 980-nm excitation [171].

\section{Photodynamic therapy}

PDT, an emerging technology for the diagnosis and treatment of diseases, uses photodynamic effects [172]. Briefly, the main treatment process is as follows: the photosensitizer is excited to generate active oxygen for example, singlet oxygen $\left({ }^{1} \mathrm{O}_{2}\right)$ - entering the organism; thereafter, it can destroy tumor cells and achieve the purpose of cancer treatment [173]. Compared to UV and visible light, NIR light has a significant advantage in penetrating human tissues, making UCNP an ideal candidate for PDT applications in deep tissue cancer therapy. Zhang et al. encapsulated the photosensitizing molecule ZnPc in the lipid micelle-modified UCNP [174]. When irradiated with $980 \mathrm{~nm}$ excitation, ZnPc produced ${ }^{1} \mathrm{O}_{2}$, which in turn killed cancer cells and detected tumor growth. Besides, the PDT which was guided by UCNPs synergistic with siRNA for tumor therapy made remarkable progress. Zhang et al. established a novel UCNP drug delivery system for the delivery of siRNA. They designed a delivery system that could be wrapped in light-tear polymer tape for efficient siRNA delivery under NIR modulation [175]. When the photocleavable linker (PhL) and PEG film are irradiated at $980 \mathrm{~nm}$, the UCNP tear off the PEG film to stimulate the activation of HA to release reactive oxygen species (ROS) in order to assist siRNA in effectively increasing gene-silencing efficiency and inhibiting tumor cell growth in vivo and 


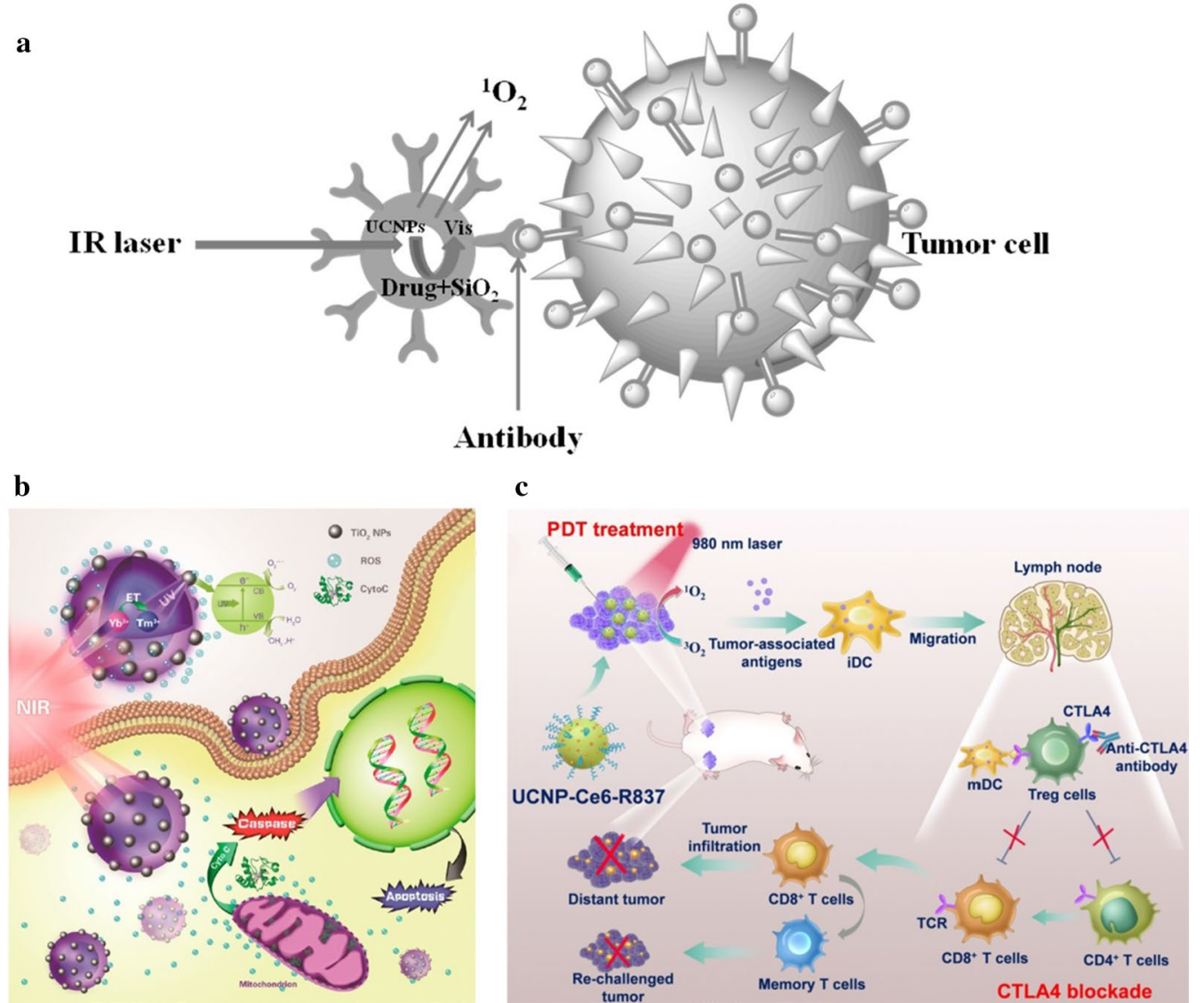

Fig. 16 a Schematic illustration of the design of UCNP based drug delivery system for photodynamic therapy. b Plot for the potential molecular mechanism of inducing apoptosis with UCNPs@TiO ${ }_{2}$-based NIR light-mediated PDT treatment [176]. c Scheme summarizing the mechanisms of combining NIR-mediated PDT with CTLA-4 checkpoint blockade for cancer immunotherapy. UCNP-Ce6-R837 nanoparticles under NIR light would enable effective photodynamic destruction of tumors [116]. ( Copyright 2015, 2017. American Chemical Society. Reproduced with permission.)

in vitro simultaneously [147]. As Fig. 16 illustrates, Hou et al. reported a novel NIR photosensitizer based on $\mathrm{TiO}_{2}$ coated UCNP core-shell nanocomposites (UCNPs@ $\mathrm{TiO}_{2} \mathrm{NCs}$ ), which could be triggered with PDT and effectively inhibit tumor growth in tumor-bearing mice because it provided better tissue penetration than UV radiation [176]. Xu et al. used a UCNP loaded with chlorin e6 (Ce6) as a photosensitizer and imiquimod (R837) as a Toll-like receptor-7 agonist. The obtained multifunctional UCNP-Ce6-R837 enhanced tissue penetration depth under NIR irradiation and this not only achieved photodynamic destruction of tumors, but also generated tumor-associated antigen libraries under the condition of adjuvant, which further promotes a strong antitumor immune response [116].

\section{Antibacterial photodynamic therapy on antibacterial and biofilms}

At present, more than $80 \%$ of human infectious diseases are related to bacterial biofilms. Biofilms can effectively protect bacteria and produce antibiotic resistance. The emergence of super-resistant bacteria and the growth of bacterial biofilms have seriously hindered the development of biomaterials. Although inorganic materials such as $\mathrm{Ag}^{+}$and $\mathrm{Cu}^{+}$have excellent antibacterial activity, the expensive cost and the toxicity caused by excessive use is a crucial problem. It is necessary to carry out simultaneous biofilm removal and sterilization synergistic treatment. aPDT drug delivery systems based on UCNPs have gradually emerged in the filed. Yue and colleagues prepared UCNPs consisting of cationic N-octyl chitosan (OC)-coated UCNPs loaded with the photosensitizer zinc phthalocyanine (OCUCNP-ZnPc) from $\mathrm{NaYF}_{4}, \mathrm{Yb}$, or Er core. They consist of a $\mathrm{NaYF}_{4}$ shell coated with chitosan and containing ZnPc, which exhibited excellent aPDT efficacy. Periodontitis is an infectious disease caused by bacterial biofilms that is usually treated by physically removing plaque with high recurrence. The aPDT method guided by UCNPs provides a novel solution to this situation. Qi and colleagues constructed an 


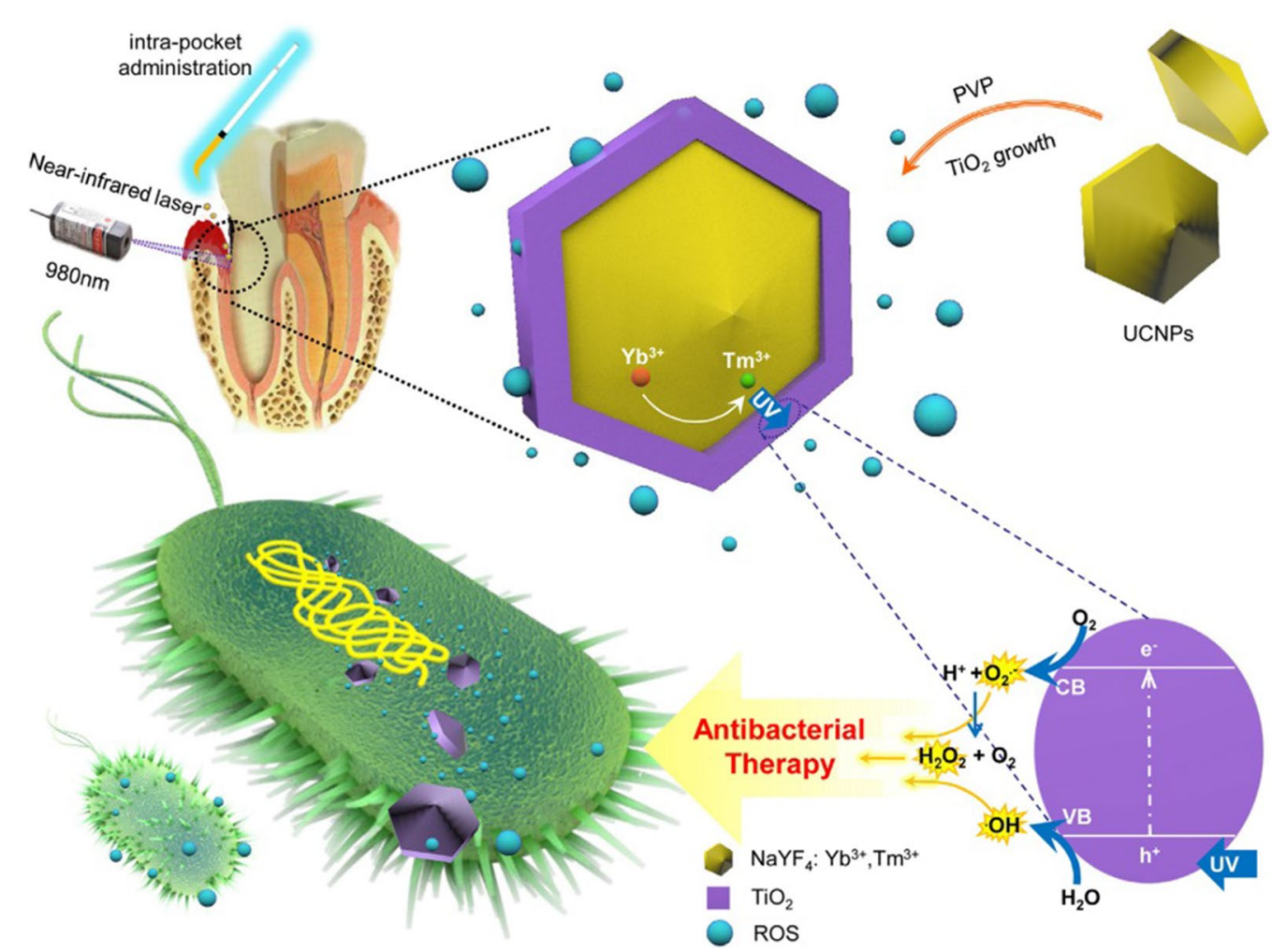

Fig. 17 Synthesis of $\mathrm{NaYF}_{4}: \mathrm{Yb}^{3+}, \mathrm{Tm}^{3+} @ \mathrm{TiO}_{2}$ and mechanism of aPDT under NIR irradiation. Upon NIR irradiation, the UCNP nucleus converts NIR light into ultraviolet (UV) light and the UV light in turn excites $\mathrm{TiO}_{2}$ to generate active oxygen, which eventually causes oxidative damage against the microorganisms. ( Copyright 2019. Elsevier. Reproduced with permission.)

aPDT using $\mathrm{NaYF}_{4}: \mathrm{Yb}^{3+}, \mathrm{Tm}^{3+} @ \mathrm{TiO}_{2}$ core-shell nanoparticles (Fig. 17). Under 980-nm excitation, UCNPs can emit strong UV light, which triggers the aPDT function of shell $\mathrm{TiO}_{2}$ through energy transfer, thereby achieving significant antibacterial effects on three periodontitis-related pathogens and biofilms [177]. In addition, Zhang et al. combined the photosensitizer Ce6 molecule with $\mathrm{NaYF}_{4}: \mathrm{Yb}, \mathrm{Er}$ by hydrophobic interaction to overcome the problem of insufficient penetration depth of PDT treatment in deep periodontal tissues [178]. Subsequently, $\mathrm{Mn}$ was doped to enhance red fluorescence, and a significant inhibitory effect on biofilms of pathogenic bacteria such as Porphyromonas gingivalis and Clostridium nucleatum was observed under NIR excitation. At present, our group is constructing an aPDT platform based on UCNPs, which is related to esophageal diseases for the removal of Porphyromonas gingivalis and its derived biofilms, and further studies on the relationship between Porphyromonas gingivalis and esophageal diseases. Taken together, NIR-triggered UCNPs aPDT has demonstrated exciting potential in the treatment of a variety of oral infectious diseases, which has broad application prospects for other bacterial infection treatments.

\section{Conclusions and future perspectives}

In this review, we briefly described the structure and energy level principle of UCNPs and introduced several methods for the synthesis and modification of UCNPs based on chemical matrix reactions. Lanthanide-based UCNPs play an excellent role in biomedical applications, especially bioimaging and disease treatment, due to their unique properties. Concerning drug delivery and release, UCNPs outperformed effectively PDT for tumors and exhibited promising clinical value. At the same time, the use of NIR light in UCNP-based aPDT in antibacterial and biofilm removal applications was a major innovation for infectious disease treatment. On the other hand, the practical applications of UCNPs still face formidable challenges that will require researchers in all disciplines to work together closely. Although these luminescent UCNPs have increased the sensitivity of biosensing and bioimaging and have photoinitiated biological and chemical reactions, they still have limited upconversion efficiencies, and considerable effort has been devoted to upconversion efficiency improvement. The narrowband NIR absorption can be expanded to a more suitable wavelength range using dye-sensitized UCNPs; however, it was extremely unstable both in vivo and in vitro. 
Nevertheless, the biomedical applications of UCNPs have been expanded in recent years despite the enormous challenges in practice. We still have reason to believe that multifunctional lanthanide-based upconversion luminescent nanomaterials have a bright future in biomedical and related fields.

\section{Acknowledgements}

Not applicable.

\section{Authors' contributions}

GL determined and summarized the main content and structure of the article HW prepared and revised the manuscript. HS collected readings and statistics; HW and edited and corrected graphics and tables; MZ, AJ, JL, and GL reviewed and modified the content of the article. All authors know and have read the contents of the article. All authors read and approved the final manuscript.

\section{Funding}

This work was financially supported by the National Natural Science Foundation of China (81741147, U1804193), Key Science and Technology Program of Henan Province (192102310189) and Innovation Scientists and Technicians Troop Construction Projects of Henan Province(CXTD2017071).

\section{Availability of data and materials}

Please contact author for data requests.

\section{Ethics approval and consent to participate}

Not applicable.

\section{Consent for publication}

Not applicable.

\section{Competing interests}

The authors declare no conflict of interest.

\author{
Author details \\ ${ }^{1}$ Medical College, Henan University of Science and Technology, Luoy- \\ ang 471023, Henan, China. ${ }^{2}$ School of Medical Technology and Engineering, \\ Henan University of Science and Technology, Luoyang 471023, China. ${ }^{3}$ School \\ of Environmental Science and Engineering, Nankai University, Tianjin, 300350, \\ China.
}

Received: 22 January 2020 Accepted: 20 October 2020

Published online: 29 October 2020

\section{References}

1. Yang MY, Yang T, Mao CB. Enhancement of photodynamic cancer therapy by physical and chemical factors. Angewandte Chem Int Ed. 2019:58:14066-80.

2. Weissleder R. A clearer vision for in vivo imaging. Nat Biotechnol. 2001;19:316-7.

3. Yang F, Chen H, Ma L, Shao B, Shuang Z, Wang Z, You H. Surfactant-free aqueous synthesis of novel Ba2GdF7:Yb3+, Er3+@PEG upconversion nanoparticles for in vivo trimodality imaging. ACS Appl Mater Interfaces. 2017;9:15096-102.

4. Bednarkiewicz A, Prorok K, Pawlyta M, Strek W. Energy migration upconversion of $\mathrm{Tb} 3+$ in $\mathrm{Yb} 3+$ and $\mathrm{Nd} 3+$ codoped active-core / activeshell NaYF4 colloidal nanoparticles. Chem Mater. 2016:28:2295-2230.

5. Wen G, Li Z, Tong C, Min L, Lu Y. Extended near-infrared photoactivity of Bi6Fe1.9Co0.1Ti3O18by upconversion nanoparticles. Nanomaterials. 2018;8:534.

6. Chen C, Fan W, Wen S, Qian PS, Wu MCL, Liu Y, Wang B, Du L, Shan X, Kianinia M. Multi-photon near-infrared emission saturation nanoscopy using upconversion nanoparticles. Nat Commun. 2018;9:3290.

7. Dukhno O, Przybilla F, Muhr V, Buchner M, Hirsch T, Mely Y. Timedependent luminescence loss of individual upconversion nanoparticles upon dilution in aqueous solutions. Nanoscale. 2018;10:15904-10.
8. Ai X, Lyu L, Zhang Y, Tang Y, Mu J, Liu F, Zhou Y, Zuo Z, Liu G, Xing B. Remote regulation of membrane channel activity by site-specific localization of lanthanide-doped upconversion nanocrystals. Angew Chem Int Ed. 2017a;129:3077-81.

9. Sun M, Xu L, Ma W, Wu X, Kuang H, Wang L, Xu C. Phototherapy: hierarchical plasmonic nanorods and upconversion core-satellite nanoassemblies for multimodal imaging-guided combination phototherapy. Adv Mater. 2016;28:898-904.

10. Hardman PJ, Clarkson WA, Friel GJ, Pollnau M. Energy-transfer upconversion and thermal lensing in high-power end-pumped Nd:YLF laser crystals. IEEE J Quantum Electron. 2017;35:647-55.

11. Ryu J, Park HY, Kim K, Kim H, Yoo JH, Kang M, Im K, Grailhe R, Song R. Facile synthesis of ultrasmall and hexagonal NaGdF4:Yb3+, Er3+ nanoparticles with magnetic and upconversion imaging properties. J Phys Chem C. 2016;114:21077-82.

12. Ai X, Lyu L, Zhang Y, Tang Y, Mu J, Liu F, Zhou Y, Zuo Z, Liu G, Xing B. Remote regulation of membrane channel activity by site-specific localization of lanthanide-doped upconversion nanocrystals. Angew Chem Int Ed. 2017b;129:3031-5.

13. Kaviyarasu K, Manikandan E, Kennedy J, Jayachandran M, Ladchumananandasiivam R, Gomes UUD, Maaza M. Synthesis and characterization studies of $\mathrm{NiO}$ nanorods for enhancing solar cell efficiency using photon upconversion materials. Ceram Int. 2016;42:8385-94.

14. Huot L, Moselund PM, Tidemand-Lichtenberg P, Leick L, Pedersen C. Upconversion imaging using an all-fiber supercontinuum source. Opt Lett. 2016;41:2466-9.

15. Huot L, Moselund PM, Leick L, Tidemandlichtenberg P, Pedersen C. Broadband upconversion imaging around $4 \mu \mathrm{m}$ using an all-fiber supercontinuum source. Spie Lase. 2017;22:36.

16. Kwon OS, Song HS, Conde J, Kim H, Artzi N, Kim JH. Dual-color emissive upconversion nanocapsules for differential cancer bioimaging in vivo. ACS Nano. 2016;10:1512-21.

17. Liang L, Care A, Zhang R, Lu Y, Packer NH, Sunna A, Qian Y, Zvyagin AV. Facile assembly of functional upconversion nanoparticles for targeted cancer imaging and photodynamic therapy. ACS Appl Mater Interfaces. 2016:8:11945-53.

18. Rao L, Meng QF, Bu LL, Cai B, Huang Q, Sun ZJ, Zhang WF, Li A, Guo SS, Liu W. Erythrocyte membrane-coated upconversion nanoparticles with minimal protein adsorption for enhanced tumor imaging. ACS Appl Mater Interfaces. 2017:9:2159-68.

19. Zhang RY, Duan YK, Liu B. Recent advances of AIE dots in NIR imaging and phototherapy. Nanoscale. 2019;11:19241-50

20. Agrawal A, Cho SH, Zandi O, Ghosh S, Johns RW, Milliron DJ. Localized surface plasmon resonance in semiconductor nanocrystals. Chem Rev. 2018;1 18:3121-207.

21. Chen S, Weitemier AZ, Zeng X, He L, Wang X, Tao Y, Huang AJY, Hashimotodani Y, Kano M, Iwasaki H, et al. Near-infrared deep brain stimulation via upconversion nanoparticle-mediated optogenetics. Science. 2018:359:679-83.

22. Du P, Luo L, Huang X, Yu JS. Ultrafast synthesis of bifunctional Er3+/ Yb3+-codoped NaBiF4 upconverting nanoparticles for nanothermometer and optical heater. J Colloid Interface Sci. 2018;514:172-81.

23. Qiu Z, Shu J, Tang D. Near-infrared-to-ultraviolet light-mediated photoelectrochemical aptasensing platform for cancer biomarker based on core shell NaYF4:Yb, Tm@TiO2 upconversion microrods. Anal Chem. 2018;90:1021-8.

24. Wu Z, Yuan X, Zeng G, Jiang L, Zhong H, Xie Y, Wang H, Chen X, Wang H. Highly efficient photocatalytic activity and mechanism of $\mathrm{Yb} 3+/$ Tm3+ codoped In2S3 from ultraviolet to near infrared light towards chromium (VI) reduction and rhodamine B oxydative degradation. Appl Catal B-Environ. 2018;225:8-21.

25. Gu B, Zhang Q. Recent advances on functionalized upconversion nanoparticles for detection of small molecules and ions in biosystems. Adv Sci. 2018:5:1700609.

26. Kim D-H, D'Aleo A, Chen X-K, Sandanayaka ADS, Yao D, Zhao L, Komino T, Zaborova E, Canard G, Tsuchiya Y, et al. High-efficiency electroluminescence and amplified spontaneous emission from a thermally activated delayed fluorescent near-infrared emitter. Nat Photonics. 2018;12:98.

27. Wang $W-N$, Huang $C-X$, Zhang $C-Y$, Zhao $M-L$, Zhang J, Chen $H-J$, Zha Z-B, Zhao T, Qian H-S. Controlled synthesis of upconverting 
nanoparticles/ZnxCd1-xS yolk-shell nanoparticles for efficient photocatalysis driven by NIR light. Appl Catal B-Environ. 2018;224:854-62.

28. Wen S, Zhou J, Zheng K, Bednarkiewicz A, Liu X, Jin D. Advances in highly doped upconversion nanoparticles. Nat Commun. 2018;9:2415.

29. Zhao J, Gao J, Xue W, Di Z, Xing H, Lu Y, Li L. Upconversion luminescence-activated DNA nanodevice for ATP sensing in living cells. J Am Chem Soc. 2018;140:578-81.

30. Zhou J, Wen S, Liao J, Clarke C, Tawfik SA, Ren W, Mi C, Wang F, Jin D. Activation of the surface dark-layer to enhance upconversion in a thermal field. Nat Photon. 2018;12:154.

31. Shi H, Liang G-F, Li Y, Li J-H, Jing A-H, Feng W-P, Li G-D, Du J-X, Feng S-Y. Preparation and evaluation of upconversion nanoparticles based miRNA delivery carrier in colon cancer mice model. J Biomed Nanotechnol. 2019;15:2240-50.

32. Zhang Y, Huang P, Wang D, Chen J, Liu W, Hu P, Huang M, Chen $X$, Chen Z. Near-infrared-triggered antibacterial and antifungal photodynamic therapy based on lanthanide-doped upconversion nanoparticles. Nanoscale. 2018;10:15485-95.

33. Zhao J, Zheng X, Schartner EP, lonescu P, Zhang R, Nguyen TL, Jin D, Ebendorff-Heidepriem $\mathrm{H}$. Glass fibers: upconversion nanocrystaldoped glass: a new paradigm for photonic materials. Adv Optical Mater. 2016:4:1419-519.

34. Tian Y, Yue T, Ping H, Lei W, Shi Q, Cui CE. Effect of Yb 3+ concentration on upconversion luminescence and temperature sensing behavior in $\mathrm{Yb} 3+/ \mathrm{Er} 3+$ co-doped $\mathrm{YNbO} 4$ nanoparticles prepared via molten salt route. Chem Eng J. 2016;297:26-34.

35. Cheng XW, Pan Y, Yuan Z, Wang XW, Su WH, Yin LS, Xie XJ, Huang L. $\mathrm{Er}^{3+}$ sensitized photon upconversion nanocrystals. Adv Func Mater. 2018;28:1800208

36. Liu Y, Kang N, Lv J, Zhou Z, Zhao Q, Ma L, Chen Z, Ren L, Nie L. Deep photoacoustic/luminescence/magnetic resonance multimodal imaging in living subjects using high-efficiency upconversion nanocomposites. Adv Mater. 2016a;28:6411-9.

37. Kim S, Hwang SH, Im SG, Lee MK, Lee CH, Sang JS, Oh HB. Upconversion nanoparticle-based förster resonance energy transfer for detecting DNA methylation. Sensors. 2016;16:1259.

38. Shangguan M, Xia H, Wang C, Qiu J, Shentu G, Zhang Q, Dou X, Pan JW. All-fiber upconversion high spectral resolution wind lidar using a Fabry-Perot interferometer. Opt Express. 2016;24:19322-36.

39. He M, Pang X, Liu X, Jiang B, He Y, Snaith H, Lin Z. Monodisperse dual-functional upconversion nanoparticles enabled near-infrared organolead halide perovskite solar cells. Angew Chem Int Ed. 2016;128:4441-541.

40. Gu ZJ, Yan L, Tian G, Li SJ, Chai ZF, Zhao YL. Recent advances in design and fabrication of upconversion nanoparticles and their safe theranostic applications. Adv Mater. 2013;25:3758-79.

41. Idris NM, Gnanasammandhan MK, Zhang J, Ho PC, Mahendran $\mathrm{R}$, Zhang $\mathrm{Y}$. In vivo photodynamic therapy using upconversion nanoparticles as remote-controlled nanotransducers. Nat Med. 2012;18:1580-U190

42. Jin B, Wang S, Lin M, Jin Y, Zhang S, Cui X, Gong Y, Li A, Xu F, Lu TJ. Upconversion nanoparticles based FRET aptasensor for rapid and ultrasenstive bacteria detection. Biosens Bioelectron. 2017:90:525-33.

43. Cheng XW, Ge H, Wei Y, Zhang K, Su WH, Zhou JM, Yin LS, Zhan QQ, Jing S, Huang L. Design for BRIGHTER PHOTON UPCONVERSION EMISSIONS VIA ENERGY LEVEL OVERLAP OF LANTHANIDE IOns. ACS Nano. 2018;12:10992-9.

44. Xie XJ, Gao NY, Deng RR, Sun Q, Xu QH, Liu XG. Mechanistic investigation of photon upconversion in Nd3+-sensitized core-shell nanoparticles. J Am Chem Soc. 2013;135:12608-11.

45. Rajeswari R, Susmitha K, Jayasankar CK, Raghavender M, Giribabu L. Enhanced light harvesting with novel photon upconverted Y2CaZnO5:Er3+/Yb3+ nanophosphors for dye sensitized solar cells. Sol Energy. 2017;157:956-65.

46. Zhou B, Shi BY, Jin DY, Liu XG. Controlling upconversion nanocrystals for emerging applications. Nat Nanotechnol. 2015;10:924-36.

47. Lu Y, Zhao J, Zhang R, Liu Y, Liu D, Goldys EM, Yang X, Peng X, Sunna A, Jie L. Tunable lifetime multiplexing using luminescent nanocrystals. Nat Photonics. 2014;8:32-6.

48. Wang HQ, Nann T. Upconverting nanoparticles. Angew Chem Int Ed. 2011;50:5808-29.
49. Feng W, Debapriya B, Yongsheng L, Xueyuan C, Xiaogang L. Upconversion nanoparticles in biological labeling, imaging, and therapy. Analyst. 2010;135:1839-54.

50. Duan CC, Liang LE, Li L, Zhang R, Xu ZP. Recent progress in upconversion luminescence nanomaterials for biomedical applications. J Mater Chem B. 2018;6:192-209.

51. Wang M, Abbineni G, Clevenger A, Mao CB, Xu SK. Upconversion nanoparticles: synthesis, surface modification and biological applications. Nanomed Nanotechnol Biol Med. 2011;7:710-29.

52. Chen DQ, Yu YL, Huang P, Wang YS. Nanocrystallization of lanthanide trifluoride in an aluminosilicate glass matrix: dimorphism and rare earth partition. CrystEngComm. 2009;11:1686-90.

53. Wang M, Mi CC, Zhang YX, Liu JL, Li F, Mao CB, Xu SK. NIR-responsive silica-coated NaYbF4:Er/Tm/Ho upconversion fluorescent nanoparticles with tunable emission colors and their applications in immunolabeling and fluorescent imaging of cancer cells. J Phys Chem C. 2009;113:19021-7.

54. Li Z, Yong Z, Shan J. Multicolor core/shell-structured upconversion fluorescent nanoparticles. Adv Mater. 2010;20:4765-9.

55. Wang F, Liu X. Upconversion multicolor fine-tuning: visible to nearinfrared emission from lanthanide-doped NaYF4 nanoparticles. J Am Chem Soc. 2008;130:5642-3.

56. Yao C, Wang P, Li X, Hu X, Hou J, Wang L, Zhang F. Near-infraredtriggered azobenzene-liposome/upconversion nanoparticle hybrid vesicles for remotely controlled drug delivery to overcome cancer multidrug resistance. Adv Mater. 2016;28:9341-8.

57. Duo F, Wang Y, Fan C, Zhang X, Wang Y. Enhanced visible light photocatalytic activity and stability of CQDs/BiOBr composites: the upconversion effect of CQDs. J Alloy Compd. 2016;685:34-41.

58. Himmelstoß SF, Wiesholler LM, Buchner M, Muhr V, MärkI S, Baeumner AJ, Hirsch T. $980 \mathrm{~nm}$ and $808 \mathrm{~nm}$ excitable upconversion nanoparticles for the detection of enzyme related reactions. SPIE BiOS. 2017;100:770L.

59. Chen F, Zhang S, Bu W, Chen Y, Xiao Q, Liu J, Xing H, Zhou L, Peng W, Shi J. A uniform sub-50 nm-sized magnetic/upconversion fluorescent bimodal imaging agent capable of generating singlet oxygen by using a 980 nm laser. Chem Eur J. 2012;18:7082-90.

60. Chen G, Qiu H, Prasad PN, Chen X. Upconversion nanoparticles: design, nanochemistry, and applications in theranostics. Chem Rev. 2014;114:5161-214.

61. Li Y, Liu W, Zhang P, Zhang H, Wu J, Ge J, Wang P. A fluorescent probe for the efficient discrimination of Cys, Hcy and GSH based on different cascade reactions. Biosens Bioelectron. 2017;90:117-24.

62. Shang Y, Hao S, Lv W, Tong C, Li T, Lei Z, Yang CH. Confining excitation energy of Er3+-sensitized upconversion nanoparticles through introducing various energy trapping centers. J Mater Chem C. 2018;6:3869-75.

63. Shanmugam V, Selvakumar S, Yeh CS. Near-infrared light-responsive nanomaterials in cancer therapeutics. Chem Soc Rev. 2014;43:6254-87.

64. Wang M, Liu JL, Zhang YX, Hou W, Wu XL, Xu SK. Two-phase solvothermal synthesis of rare-earth doped NaYF 4 upconversion fluorescent nanocrystals. Mater Lett. 2009;63:325-7.

65. Zhang Y, Lu Y. DekangXu, Hao L, Yang S: Controlled synthesis and luminescence properties of $\beta-\mathrm{NaGdF} 4: \mathrm{Yb} 3+$, Er3 + upconversion nanoparticles. J Crystal Growth. 2018;2018:116-9.

66. Zuo J, Li Q, Xue B, Li C, Chang Y, Zhang Y, Liu X, Tu L, Zhang H, Kong X. Employing shells to eliminate concentration quenching in photonic upconversion nanostructure. Nanoscale. 2017;9:7941-6.

67. Rui W, Fan Z. NIR luminescent nanomaterials for biomedical imaging. Journal of Materials Chemistry B. 2014;2:2422-43.

68. He S, Johnson NJJ, Huu VAN, Huang YR, Almutairi A. Leveraging spectral matching between photosensitizers and upconversion nanoparticles for $808 \mathrm{~nm}$-activated photodynamic therapy. Chem Mater. 2018;30:3991-4000.

69. Martinez R, Polo E, Barbosa S, Taboada P, del Pino P, Pelaz B. 808 nmactivable core@multishell upconverting nanoparticles with enhanced stability for efficient photodynamic therapy. J Nanobiotechnol. 2020;18:85

70. Zhang Y, Zhang L, Deng R, Tian J, Zong Y, Jin D, Liu X. Multicolor barcoding in a single upconversion crystal. J Am Chem Soc. 2014;136:4893-6.

71. Xun W, Jing Z, Qing P, Yadong L. A general strategy for nanocrystal synthesis. Nature. 2005;437:121-4. 
72. Fu SB, Chen BJ, Zhang JS, Li XP, Zhong H, Tian BN, Wang YZ, Sun M, Zhang $X Q$, Cheng LH. High upconversion optical gain of Er 3+-doped tellurite glass. Appl Phys A. 2014;115:1329-33.

73. Gnanasammandhan MK, Idris NM, Bansal A, Huang K, Zhang Y. Near-IR photoactivation using mesoporous silica-coated NaYF4:Yb Er/Tm upconversion nanoparticles. Nat Protocols. 2016;11:688-713.

74. Sun H, Zhang L, Liao M, Zhou G, Yu C, Zhang J, Hu L, Jiang Z. Host dependent frequency upconversion of Er3+-doped oxyfluoride germanate glasses. J Lumin. 2006:117:179-86.

75. Wang X, Li X, Ito A, Yoshiyuki K, Sogo Y, Watanabe Y, Yamazaki A, Ohno T, Tsuji NM. Hollow structure improved anti-cancer immunity of mesoporous silica nanospheres in vivo. Small. 2016;12:3602-02.

76. Li J, Zhu X, Xue M, Feng W, Ma R, Li F. Nd ${ }^{3+}$-sensitized upconversion nanostructure as a dual-channel emitting optical probe for near infrared-to-near infrared fingerprint imaging. Inorg Chem. 2016:55:10278-83.

77. Zhang D, Wei L, Zhong M, Xiao L, Li HW, Wang J. The morphology and surface charge-dependent cellular uptake efficiency of upconversion nanostructures revealed by single particle optical microscopy. Chem Sci. 2018;9:5260-9.

78. Li S, Xu LG, Ma W, Wu XL, Sun MZ, Kuang H, Wang LB, Kotov NA, Xu $C L$. Dual-mode ultrasensitive quantification of microrna in living cells by chiroplasmonic nanopyramids self-assembled from gold and upconversion nanoparticles. J Am Chem Soc. 2016;138:306-12.

79. Hou Z, Zhang Y, Deng K, Chen Y, Li X, Deng X, Cheng Z, Lian H, Li C, Lin J: UV-emitting upconversion-based $\mathrm{TiO}_{2}$ photosensitizing nanoplatform: near-infrared light mediated in vivo photodynamic therapy via mitochondria-involved Zdaee5Apoptosis pathway. Acs Nano 2015; 9:2584-99.

80. Li Z. Zhang Y. Gang H: Lanthanide-doped upconversion nanoparticles for imaging-guided drug delivery and therapy; 2016. p. 139-64.

81. Xia H, Shangguan M, Wang C, Shentu G, Qiu J, Zhang Q, Dou X, Pan J. Micro-pulse upconversion Doppler lidar for wind and visibility detection in the atmospheric boundary layer. Opt Lett. 2016;41:5218-21.

82. Han XB, Li HX, Jiang YQ, Wang H, Li XS, Kou JY, Zheng YH, Liu ZN, Li $\mathrm{H}$, Li J. Upconversion nanoparticle-mediated photodynamic therapy induces autophagy and cholesterol efflux of macrophage-derived foam cells via ROS generation. Cell Death Dis. 2017;8:e2864.

83. Basavapoornima C, Linganna K, Kesavulu CR, Ju S, Kim BH, Han WT, Jayasankar CK. Spectroscopic and pump power dependent upconversion studies of $\mathrm{Er}^{3+}$-doped lead phosphate glasses for photonic applications. J Alloy Compd. 2016;699:959-68.

84. Yin Z, Li H, Xu W, Cui S, Zhou D, Chen X, Zhu Y, Qin G, Song H. Local field modulation induced three-order upconversion enhancement: combining surface plasmon effect and photonic crystal effect. Adv Mater. 2016;28:2518-25.

85. Rinkel T, Raj AN, Duehnen S, Haase M. Synthesis of 10nm-NaYF4:Yb, Er/NaYF4 core/shell upconversion nanocrystals with $5 \mathrm{~nm}$ particle cores. Angewandte Chem Int Ed. 2016;55:1164-7.

86. Yang C, Guo Y, Han P, Dan L, Xin G, Zhang Z, Kai F, Chu M. Graphitic carbon nanocages as new photothermal agent and drug Carrier for 980-nm-laser-driven cancer therapy. Carbon. 2018;136:234-47.

87. Du H, Yu J, Guo D, Yang W, Wang J, Zhang B. Improving the MR imaging sensitivity of upconversion nanoparticles by an internal and external incorporation of the $\mathrm{Gd}^{3+}$ strategy for in vivo tumor-targeted imaging. Langmuir Acs J Surfaces Colloids. 2016;32:1155-65.

88. Luoshan M, Bai L, Bu C, Liu X, Zhu Y, Guo K, Jiang R, Li M, Zhao $X$. Surface plasmon resonance enhanced multi-shell-modified upconversion NaYF 4: Yb 3+, Er 3+ @SiO $2 @ A u @ T i O 2$ crystallites for dye-sensitized solar cells. J Power Sources. 2016;307:468-73.

89. Tian G, Gu Z, Zhou L, Yin W, Liu X, Yan L, Jin S, Ren W, Xing G, Li S. $\mathrm{Mn}^{2+}$ dopant-controlled synthesis of NaYF4:Yb/Er upconversion nanoparticles for in vivo imaging and drug delivery. Adv Mater. 2012:24:1226-31

90. Yi Z, Li X, Xue Z, Liang X, Lu W, Peng H, Liu H, Zeng S, Hao J. Remarkable NIR enhancement of multifunctional nanoprobes for in vivo trimodal bioimaging and upconversion Optical/T-2-weighted MRIguided small tumor diagnosis. Adv Func Mater. 2016;25:7102-02.

91. He M, Li Z, Ge Y, Liu Z. Portable upconversion nanoparticlesbased paper device for field testing of drug abuse. Anal Chem. 2016:88:1530-4.
92. Yao W, Tian Q, Liu J, Wu Z, Cui S, Ding J, Dai Z, Wu W. Large-scale synthesis and screen printing of upconversion hexagonal-phase NaYF4:Yb3+, Tm3+/Er3+/Eu3 + plates for security applications. J Mater Chem C. 2016;4:6327-35.

93. Peng H-Y, Ding B-B, Ma Y-C, Sun S-Q, Tao W, Guo Y-C, Guo H-C, Yang X-Z, Qian H-S. Sequential growth of sandwiched NaYF4:Yb/Er@ NaYF4:Yb@NaNdF4: Yb core-shell-shell nanoparticles for photodynamic therapy. Appl Surf Sci. 2015;357:2408-14.

94. Su Q, Feng W, Yang D, Li F. Resonance energy transfer in upconversion nanoplatforms for selective biodetection. Acc Chem Res. 2016;50:32-40.

95. Marian CM. Mechanism of the triplet-to-Singlet upconversion in the assistant dopant ACRXTN. J Phys Chem C. 2017;120:3715-21.

96. Shibu ES, Hamada M, Murase N, Biju V. Nanomaterials formulations for photothermal and photodynamic therapy of cancer. J Photochem Photobiol, C. 2013;15:53-72.

97. Liu K, Liu XM, Zeng QH, Zhang YL, Tu LP, Liu T, Kong XG, Wang YH, Cao F, Lambrechts SAG, et al. Covalently assembled NIR nanoplatform for simultaneous fluorescence imaging and photodynamic therapy of cancer cells. ACS Nano. 2012;6:4054-62.

98. Xiang J, Xu L, Gong H, Zhu W, Wang C, Xu J, Feng L, Cheng L, Peng R, Liu Z. Antigen-loaded upconversion nanoparticles for dendritic cell stimulation, tracking, and vaccination in dendritic cell-based immunotherapy. ACS Nano. 2015;9:6401-11.

99. Campos-Goncalves I, Costa BFO, Santos RF, Duraes L. Superparamagnetic core-shell nanocomplexes doped with Yb3+:Er3+/Ho3+ rareearths for upconversion fluorescence. Mater Des. 2017;130:263-74.

100. Xu ZH, Kang XJ, Li CX, Hou ZY, Zhang CM, Yang DM, Li GG, Lin J. Ln(3+) (Ln Eu, Dy, Sm, and Er) ion-doped YVO4 Nano/microcrystals with multiform morphologies: hydrothermal synthesis, growing mechanism, and luminescent properties. Inorg Chem. 2010;49:6706-15.

101. Tang S, Huang ML, Wang JL, Yu FD, Shang GL, Wu JH. Hydrothermal synthesis and luminescence properties of GdVO4:Ln(3+) $(\mathrm{Ln}=\mathrm{Eu}, \mathrm{Sm}$, Dy) phosphors. J Alloy Compd. 2012;513:474-80.

102. Boyer J-C, Vetrone F, Cuccia LA, Capobianco JA. Synthesis of colloidal upconverting NaYF4 nanocrystals doped with Er3+, Yb3+ and Tm3+, $\mathrm{Yb3}+$ via thermal decomposition of lanthanide trifluoroacetate precursors. J Am Chem Soc. 2006:128:7444-5.

103. Zhang KK, Zhao Q, Qin SR, Fu Y, Liu RZ, Zhi JF, Shan CX. Nanodiamonds conjugated upconversion nanoparticles for bio-imaging and drug delivery. J Colloid Interface Sci. 2019;537:316-24.

104. Li XM, Zhang F, Zhao DY. Lab on upconversion nanoparticles: optical properties and applications engineering via designed nanostructure. Chem Soc Rev. 2015;44:1346-78.

105. Dhal S, Pal K, Banerjee I, Giri S. Upconversion nanoparticle incorporated oleogel as probable skin tissue imaging agent. Chem Eng J. 2020;379:122272.

106. Wilhelm S, Kaiser M, Wurth C, Heiland J, Carrillo-Carrion C, Muhr V, Wolfbeis OS, Parak WJ, Resch-Genger U, Hirsch T. Water dispersible upconverting nanoparticles: effects of surface modification on their luminescence and colloidal stability. Nanoscale. 2015;7:1403-10.

107. Jing Z, Qian L, Wei F, Yun S, Fuyou L. Upconversion luminescent materials: advances and applications. Chem Rev. 2014;115:395-465.

108. Mao LL, Lu ZX, He NY, Zhang LM, Deng Y, Duan DM. A new method for improving the accuracy of miRNA detection with NaYF4:Yb Er upconversion nanoparticles. Sci China Chem. 2017;60:157-62.

109. Liu B, Li CX, Xing BG, Yang PP, Lin J. Multifunctional UCNPs@PDA-ICG nanocomposites for upconversion imaging and combined photother$\mathrm{mal} /$ photodynamic therapy with enhanced antitumor efficacy. J Mater Chem B. 2016:4:4884-94.

110. Zhang $L P$, Ling $B$, Wang $L$, Chen HQ. A near-infrared luminescent $M n 2+-$ doped NaYF4:Yb, Tm/Fe3+ upconversion nanoparticles redox reaction system for the detection of GSH/Cys/AA. Talanta. 2017;172:95-101.

111. Zhao J, Sun Y, Kong X, Tian L, Wang Y, Tu L, Zhao J, Zhang H. Controlled synthesis, formation mechanism, and great enhancement of red upconversion luminescence of NaYF4:Yb3+, Er3+ nanocrystals/submicroplates at low doping level. J Phys Chem B. 2008;112:15666-72.

112. Rubner MM, Achatz DE, Mader HS, Stolwijk JA, Wegener J, Harms GS, Wolfbeis OS, Wagenknecht HA. DNA "Nanolamps": "Clicked" DNA conjugates with photon upconverting nanoparticles as highly emissive biomaterial. ChemPlusChem. 2012;77:129-34. 
113. Shao H, Xu D, Ding YD, Hong X, Liu YC. An "off-on" colorimetric and fluorometric assay for $\mathrm{Cu}(\mathrm{II})$ based on the use of NaYF4:Yb(III), $\operatorname{Er}(\mathrm{III})$ upconversion nanoparticles functionalized with branched polyethylenimine. Microchim Acta. 2018;185:211.

114. Lai JP, Shah BR, Zhang YX, Yang LT, Lee KB. Real-time monitoring of ATPResponsive Drug Release Using Mesoporous-Silica-Coated Multicolor Upconversion Nanoparticles. ACS Nano. 2015;9:5234-45.

115. Kamimura M, Miyamoto D, Saito Y, Soga K, Nagasaki Y. Design of poly(ethylene glycol)/streptavidin coimmobilized upconversion nanophosphors and their application to fluorescence biolabeling. Langmuir. 2008;24:8864-70

116. Xu J, Xu LG, Wang CY, Yang R, Zhuang Q, Han X, Dong ZL, Zhu WW, Peng R, Liu Z. Near-infrared-triggered photodynamic therapy with multitasking upconversion nanoparticles in combination with checkpoint blockade for immunotherapy of colorectal cancer. ACS Nano. 2017:11:4463-74.

117. Wang X, Liang GF, Hao XQ, Feng SY, Dai L, An JL, Li JH, Shi H, Feng WP, Zhang X. Bioinspired drug delivery carrier for enhanced tumortargeting in melanoma mice model. J Biomed Nanotechnol. 2019:15:1482-91.

118. Zhang J, Yuan ZF, Wang Y, Chen WH, Luo GF, Cheng SX, Zhuo RX, Zhang $X Z$. Multifunctional envelope-type mesoporous silica nanoparticles for tumor-triggered targeting drug delivery. J Am Chem Soc. 2013;135:5068-73.

119. Liu B, Li CX, Ma PA, Chen YY, Zhang YX, Hou ZY, Huang SS, Lin J. Multifunctional NaYF4:Yb, Er@mSiO(2)@Fe3O4-PEG nanoparticles for UCL/ MR bioimaging and magnetically targeted drug delivery. Nanoscale. 2015;7:1839-48

120. Mi CC, Zhang JP, Gao HY, Wu XL, Wang M, Wu YF, Di YQ, Xu ZR, Mao CB, Xu SK. Multifunctional nanocomposites of superparamagnetic (Fe3O4) and NIR-responsive rare earth-doped up-conversion fluorescent (NaYF4: Yb, Er) nanoparticles and their applications in biolabeling and fluorescent imaging of cancer cells. Nanoscale. 2010;2:1141-8.

121. Sun J, Song LJ, Fan Y, Tian LM, Luan SF, Niu SC, Ren LQ, Ming WH, Zhao J. Synergistic photodynamic and photothermal antibacterial nanocomposite membrane triggered by single NIR light source. ACS Appl Mater Interfaces. 2019;11:26581-9.

122. Zhao B, Qi N, Zhang KQ, Gong X. Fabrication of freestanding silk fibroin films containing Ag nanowires/NaYF4:Yb, Er nanocomposites with metal-enhanced fluorescence behavior. Phys Chem Chem Phys. 2016;18:15289-94.

123. Nagai A, Miller JB, Kos P, Elkassih S, Hu X, Siegwart DJ. Tumor imaging based on photon upconversion of $\mathrm{Pt}(\mathrm{II})$ porphyrin rhodamine co-modified NIR excitable cellulose enhanced by aggregation. Acs Biomater. 2016;1:1206-10

124. Rinkel T, Raj AN, Dühnen S, Haase M. Synthesis of $10 \mathrm{~nm} \beta-N a Y F 4: Y b, E r /$ NaYF4 core/shell upconversion nanocrystals with $5 \mathrm{~nm}$ particle cores. Angew Chem Int Ed Engl. 2016;55:1164-7.

125. Wang F, Banerjee D, Liu Y, Chen X, Liu X. Upconversion nanoparticles in biological labeling, imaging, and therapy. Analyst. 2010;135:1839-54.

126. Yao L, Zhou J, Liu J, Feng W, Li F. Iridium-complex-modified upconversion nanophosphors for effective LRET detection of cyanide anions in pure water. Adv Func Mater. 2012:22:2667-72.

127. Vedunova MV, Mishchenko TA, Mitroshina EV, Ponomareva NV, Yudintsev AV, Generalova AN, Deyev SM, Mukhina IV, Semyanov AV, Zvyagin AV. Cytotoxic effects of upconversion nanoparticles in primary hippocampal cultures. Rsc Adv. 2016;6:33656-65.

128. Lin H, YU T, Tsang MK, Bai G, Zhang Q, Hao J. Near-infrared-to-nearinfrared down-shifting and upconversion luminescence of KY3F10 with single dopant of Nd3+ ion. Appl Phys Lett. 2016;108:041092.

129. Ma Y, Ji Y, You M, Wang S, Dong Y, Jin G, Lin M, Wang Q, Li A, Zhang X. Labeling and long-term tracking of bone marrow mesenchymal stem cells in vitro using NaYF4:Yb(3+), Er(3+) upconversion nanoparticles. Acta Biomater. 2016:42:199-208.

130. Wang M, Hou W, Mi CC, Wang WX, Xu ZR, Teng HH, Mao CB, Xu SK. Immunoassay of goat antihuman immunoglobulin $\mathrm{G}$ antibody based on luminescence resonance energy transfer between near-infrared responsive NaYF4:Yb, Er upconversion fluorescent nanoparticles and gold nanoparticles. Anal Chem. 2009;81:8783-9.

131. Ramirez-Garcia G, Panikar SS, Lopez-Luke T, Piazza V, Honorato-Colin MA, Camacho-Villegas T, Hernandez-Gutierrez R, De la Rosa E. An immunoconjugated up-conversion nanocomplex for selective imaging and photodynamic therapy against HER2-positive breast cancer. Nanoscale. 2018:10:10154-65.

132. Zhou AG, Wei YC, Chen Q, Xing D. In vivo near-infrared photodynamic therapy based on targeted upconversion nanoparticles. J Biomed Nanotechnol. 2015;11:2003-10.

133. Chowdhuri AR, Laha D, Chandra S, Karmakar P, Sahu SK. Synthesis of multifunctional upconversion NMOFs for targeted antitumor drug delivery and imaging in triple negative breast cancer cells. Chem Eng J. 2017;319:200-11.

134. Dai SL, Wu SJ, Duan N, Wang ZP. A luminescence resonance energy transfer based aptasensor for the mycotoxin Ochratoxin A using upconversion nanoparticles and gold nanorods. Microchim Acta. 2016:183:1909-16.

135. Hlavã A, Farka Z, Hãbner M, Horå KV, Nämeä ED, Niessner R, Sklã DP, Knopp D, Gorris HH. Competitive upconversion-linked immunosorbent assay for the sensitive detection of diclofenac. Anal Chem. 2016;88:6011-7.

136. Huang X. Broadband dye-sensitized upconversion: a promising new platform for future solar upconverter design. J Alloy Compd. 2017:690:356-9.

137. Yanai N, Kimizuka N. Recent emergence of photon upconversion based on triplet energy migration in molecular assemblies. Chem Commun. 2016;52:5354-70.

138. Wu S, Butt HJ. Near-infrared-sensitive materials based on upconverting nanoparticles. Adv Mater. 2016;28:1208-26.

139. Zhan QQ, Qian J, Liang HJ, Somesfalean G, Wang D, He SL, Zhang ZG, Andersson-Engels S. Using $915 \mathrm{~nm}$ Laser excited Tm3+/Er3+/ Ho3+-doped NaYbF4 upconversion nanoparticles for in vitro and deeper in vivo bioimaging without overheating irradiation. ACS Nano. 2011:5:3744-57.

140. Chatterjee DK, Rufaihah AJ, Zhang Y. Upconversion fluorescence imaging of cells and small animals using lanthanide doped nanocrystals. Biomaterials. 2008;29:937-43.

141. Wenyan Y, Lina Z, Liangjun Z, Zhanjun G, Xiaoxiao L, Gan T, Shan J, Liang $Y$, Wenlu R, Gengmei X. Enhanced red emission from GdF3:Yb ${ }^{3+}, \mathrm{Er}^{3+}$ upconversion nanocrystals by Li+ doping and their application for bioimaging. Chem Eur J. 2012;18:9239-45.

142. Liu Y, Kang N, Lv J, Zhou Z, Zhao Q, Ma L, Chen Z, Ren L, Nie L. Deep photoacoustic/luminescence/magnetic resonance multimodal imaging in living subjects using high-efficiency upconversion nanocomposites. Adv Mater. 2016b:28:6411.

143. Wei R, Wei Z, Sun L, Zhang JZ, Liu J, Ge X, Shi L. Nile red derivativemodified nanostructure for upconversion luminescence sensing and intracellular detection of Fe3+ and MR imaging. ACS Appl Mater Interfaces. 2016:8:400-10.

144. Xue Z, Hou Z, Wang S, Xiaodan HU, Haoran LU, Niu C, Wang H. Research progress of up-conversion tellurite glass. Ordnance Mater Sci Eng. 2010;33:92-6.

145. Wu X, Chen G, Shen J, Li Z, Zhang Y, Han G. Upconversion nanoparticles: a versatile solution to multiscale biological imaging. Bioconjug Chem. 2015;26:166-75

146. Xiong LQ, Chen ZG, Tian QW, Cao TY, Xu CJ, Li FY. High contrast upconversion luminescence targeted imaging in vivo using peptide-labeled nanophosphors. Anal Chem. 2009:81:8687-94.

147. Zhang X, Ai F, Sun T, Wang F, Zhu G. Multimodal upconversion nanoplatform with a mitochondria-targeted property for improved photodynamic therapy of cancer cells. Inorg Chem. 2016;55:3872-80.

148. Liu QX, Chen ZY, Hong F, Liu GX, Yu WS, Song C, Wang JX, Dong XT. Multifunctional beta-NaGdF4: $\operatorname{Ln}(3+)(\mathrm{Ln}=\mathrm{Yb} / \mathrm{Er} / \mathrm{Eu})$ phosphors synthesized by L-arginine assisted hydrothermal method and their multicolor tunable luminescence. Mater Res Bull. 2019:110:141-8.

149. Liu Z, Pu F, Huang S, Yuan QH, Ren JS, Qu XG. Long-circulating Gd2O3:Yb $\mathrm{Yb}^{3+}, \mathrm{Er}^{3+}$ up-conversion nanoprobes as high-performance contrast agents for multi-modality imaging. Biomaterials. 2013:34:1712-21.

150. Ju Q, Tu DT, Liu YS, Li RF, Zhu HM, Chen JC, Chen Z, Huang MD, Chen $\mathrm{XY}$. Amine-functionalized lanthanide-doped KGdF4 nanocrystals as potential optical/magnetic multimodal bioprobes. J Am Chem Soc. 2012;134:1323-30. 
151. Zeng SJ, Tsang MK, Chan CF, Wong KL, Fei B, Hao JH. Dual-modal fluorescent/magnetic bioprobes based on small sized upconversion nanoparticles of amine-functionalized BaGdF5:Yb/Er. Nanoscale. 2012;4:5118-24

152. Zhou J, Sun Y, Du X, Xiong L, Hu H, Li F. Dual-modality in vivo imaging using rare-earth nanocrystals with near-infrared to near-infrared (NIRto-NIR) upconversion luminescence and magnetic resonance properties. Biomaterials. 2010;31:3287-95.

153. Rieffel J, Chen F, Kim J, Chen GY, Shao W, Shao S, Chitgupi U, Hernandez R, Graves SA, Nickles RJ, et al. Hexamodal imaging with porphyrin-phospholipid-coated upconversion nanoparticles. Adv Mater. 2015;27:1785.

154. Chang SL. Highly modulated structure and upconversion photoluminescence properties of $\mathrm{PbGd} 2$ (MoO 4) $4: \mathrm{Er}^{3+} / \mathrm{Yb}^{3+}$ phosphors. Mater Res Bull. 2016a;75:211-6.

155. Chen G, Jaskula-Sztul R, Esquibel CR, Lou I, Zheng Q, Dammalapati A, Harrison A, Eliceiri KW, Tang W, Chen H, Gong S. Neuroendocrine tumortargeted upconversion nanoparticle-based micelles for simultaneous nir-controlled combination chemotherapy and photodynamic therapy, and fluorescence imaging. Adv Func Mater. 2017;27:1604671.

156. Han S, Samanta A, Xie X, Huang L, Peng J, Park SJ, Teh DBL, Choi Y, Chang $Y-T$, All AH, et al. Gold and hairpin DNA functionalization of upconversion nanocrystals for imaging and in vivo drug delivery. Adv Mater. 2017;29:1700244

157. Peng J, Samanta A, Zeng X, Han S, Wang L, Su D, Loong DTB, Kang $\mathrm{N}-\mathrm{Y}$, Park S-J, All AH, et al. Real-time in vivo hepatotoxicity monitoring through chromophore-conjugated photon-upconverting nanoprobes. Angewandte Chem Int Ed. 2017:56:4165-9.

158. Chang SL. Microwave sol-gel derived $\mathrm{NaCaGd}(\mathrm{MoO} 4) 3: \mathrm{Er}^{3+} / \mathrm{Yb}^{3+}$ phosphors and their upconversion photoluminescence properties. Infrared Phys Technol. 2016b;76:353-9.

159. Peng $D$, Huang $X, Y u$ JS. Yb3+-Concentration dependent upconversion luminescence and temperature sensing behavior in $\mathrm{Yb3}+/ \mathrm{Er} 3+$ codoped Gd2MoO6 nanocrystals prepared by a facile citric-assisted sol-gel method. Inorg Chem Front. 2017;4:1987-95.

160. Guan Y, Lu H, Li W, Zheng Y, Jiang Z, Zou J, Gao H. Near-infrared triggered upconversion polymeric nanoparticles based on aggregationinduced emission and mitochondria targeting for photodynamic cancer therapy. ACS Appl Mater Interfaces. 2017;9:26731-9.

161. Zhao N, Wu B, Hu X, Xing D. NIR-triggered high-efficient photodynamic and chemo-cascade therapy using caspase-3 responsive functionalized upconversion nanoparticles. Biomaterials. 2017;141:40-9.

162. Yang DM, Ma PA, Hou ZY, Cheng ZY, Li CX, Lin J. Current advances in lanthanide ion ( $\mathrm{Ln}(3+))$-based upconversion nanomaterials for drug delivery. Chem Soc Rev. 2015;44:1416-48.

163. Liu FY, He XX, Lei Z, Liu L, Zhang JP, You HP, Zhang HM, Wang ZX. Facile preparation of doxorubicin-loaded Upconversion@Polydopamine nanoplatforms for simultaneous in vivo multimodality imaging and chemophotothermal synergistic therapy. Adv Healthcare Mater. 2015:4:559-68.

164. Guo S, Tsang MK, Lo WS, Hao J, Wong WT. 808 nm excited energy migration upconversion nanoparticles driven by a $\mathrm{Nd} 3+-$ Trinity system with color-tunability and superior luminescence properties. Nanoscale. 2018;10:2790-803.

165. Bi H, Fei H, Dai Y, Xu J, Dong Y, Dan Y, Gai S, Li L, Li C, Yang P. Quad-model imaging-guided high-efficiency phototherapy based on upconversion nanoparticles and ZnFe2O4 integrated graphene oxide. Inorg Chem. 2018;57:9988-98.

166. Bao WE, Liu XW, Lv YL, Lu GH, Li F, Zhang F, Liu B, Li D, Wei W, Li Y. Nanolongan with multiple on-demand conversions for ferroptosis-apoptosis combined anticancer therapy. ACS Nano. 2019;13:260-73.

167. Wang X, Valiev RR, Ohulchanskyy TY. H A, Yang C, Chen G: Dye-sensitized lanthanide-doped upconversion nanoparticles. Chem Soc Rev. 2017;46:4150-67.

168. Kassab LRP, Kumada DK, Silva DMD, Garcia JAM. Enhanced infrared-tovisible frequency upconversion in $\mathrm{Yb} 3+/ \mathrm{Er} 3+$ codoped $\mathrm{Bi}_{2} \mathrm{O}_{3}-\mathrm{GeO}_{2}$ glasses with embedded silver nanoparticles. J Non Crystall Solids. 2018:498:395-400.

169. Li Z, Chen H, Wang C, Chen L, Liu J, Liu R. Efficient photopolymerization of thick pigmented systems using upconversion nanoparticles-assisted photochemistry. J Polym Sci Part A. 2018;56:94-1002.

170. Li X, Wei L, Pan L, Yi Z, Wang X, Ye Z, Xiao L, Li HW, Wang J. Homogeneous immunosorbent assay based on single-particle enumeration using upconversion nanoparticles for the sensitive detection of cancer biomarkers. Anal Chem. 2018;14:60-6.

171. Liu J, Bu W, Pan L, Shi J. NIR-triggered anticancer drug delivery by upconverting nanoparticles with integrated azobenzene-modified mesoporous silica. Angewandte Chem Int Ed. 2013;52:4375-9.

172. Wang C, Cheng L, Liu Y, Wang X, Ma X, Deng Z, Li Y, Liu Z. Biomedical applications: imaging-guided ph-sensitive photodynamic therapy using charge reversible upconversion nanoparticles under near-infrared light. Adv Funct Mater. 2013;23:3018-18.

173. Wang C, Cheng L, Liu Z. Upconversion nanoparticles for photodynamic therapy and other cancer therapeutics. Theranostics. 2013;3:317-30.

174. Cui S, Chen H, Zhu H, Tian J, Chi X, Qian Z, Achilefu S, Gu Y. Amphiphilic chitosan modified upconversion nanoparticles for in vivo photodynamic therapy induced by near-infrared light. J Mater Chem. 2012;22:4861-73.

175. Dou QQ, Teng CP, Ye E, Loh XJ. Effective near-infrared photodynamic therapy assisted by upconversion nanoparticles conjugated with photosensitizers. Int J Nanomed. 2015;2015:419-32.

176. Hou ZY, Zhang YX, Deng KR, Chen YY, Li XJ, Deng XR, Cheng ZY, Lian $\mathrm{HZ}$, Li CX, Lin J. UV-emitting upconversion-based $\mathrm{TiO}_{2}$ photosensitizing nanoplatform: near-infrared light mediated in vivo photodynamic therapy via mitochondria-involved apoptosis pathway. ACS Nano. 2015:9:2584-99.

177. Qi M, Li X, Sun X, Li C, Tay FR, Weir MD, Dong B, Zhou Y, Wang L, Xu HHK. Novel nanotechnology and near-infrared photodynamic therapy to kill periodontitis-related biofilm pathogens and protect the periodontium. Dent Mater. 2019;35:1665-81.

178. Zhang T, Ying D, Qi M, Li X, Zhou Y. Anti-biofilm property of bioactive upconversion nanocomposites containing chlorin e6 against periodontal pathogens. Molecules. 2019;24:2692.

\section{Publisher's Note}

Springer Nature remains neutral with regard to jurisdictional claims in published maps and institutional affiliations.

Ready to submit your research? Choose BMC and benefit from

- fast, convenient online submission

- thorough peer review by experienced researchers in your field

- rapid publication on acceptance

- support for research data, including large and complex data types

- gold Open Access which fosters wider collaboration and increased citations

- maximum visibility for your research: over 100M website views per year

At BMC, research is always in progress.

Learn more biomedcentral.com/submissions 